\title{
antibodies
}

ISSN 2073-4468

www.mdpi.com/journal/antibodies

Article

\section{Isolation of Panels of Llama Single-Domain Antibody Fragments Binding All Nine Neuraminidase Subtypes of Influenza A Virus}

\author{
Michiel M. Harmsen ${ }^{1}{ }^{1}$, , Juliette C. Blokker ${ }^{1}$, Sylvia B. Pritz-Verschuren ${ }^{1}$, Willem Bartelink ${ }^{1,2}$, \\ Herman van der Burg ${ }^{1}$ and Guus Koch ${ }^{1}$ \\ 1 Central Veterinary Institute of Wageningen UR (CVI), P.O. Box 65, 8200 AB Lelystad, The \\ Netherlands; E-Mails: jcblokker@solcon.nl (J.C.B.); Sylvia.Pritz-Verschuren@wur.nl (S.B.P.-V.); \\ willembartelink@hotmail.com (W.B.); h.burg@zonnet.nl (H.B.); Guus.Koch@wur.nl (G.K.) \\ 2 Virology Division, Department of Infectious Diseases \& Immunology, Faculty of Veterinary \\ Medicine, Utrecht University, Yalelaan 1, 3584 CL, Utrecht, The Netherlands \\ * Author to whom correspondence should be addressed; E-Mail: Michiel.harmsen@wur.nl; \\ Tel.: +31-320-238436; Fax: +31-230-238668.
}

Received: 16 February 2013; in revised form: 3 March 2013 / Accepted: 25 March 2013 / Published: 10 April 2013

\begin{abstract}
Avian influenza A virus comprises sixteen hemagglutinin (HA) and nine neuraminidase (NA) subtypes (N1-N9). To isolate llama single-domain antibody fragments (VHHs) against all $\mathrm{N}$ subtypes, four llamas were immunized with mixtures of influenza viruses. Selections using influenza virus yielded predominantly VHHs binding to the highly immunogenic HA and nucleoprotein. However, selection using enzymatically active recombinant NA (rNA) protein enabled us to isolate NA binding VHHs. Some isolated VHHs cross-reacted to other $\mathrm{N}$ subtypes. These were subsequently used for the capture of $\mathrm{N}$ subtypes that could not be produced as recombinant protein (rN6) or were enzymatically inactive (rN1, rN5) in phage display selection, yielding novel VHHs. In total we isolated 188 NA binding VHHs, 64 of which were expressed in yeast. Most VHHs specifically recognize a single $\mathrm{N}$ subtype, but some VHHs cross-react with other $\mathrm{N}$-subtypes. At least one VHH bound to all N subtypes, except N4, identifying a conserved antigenic site. Thus, this work (1) describes methods for isolating NA binding VHHs, (2) illustrates the suitability of llama immunization with multiple antigens for retrieving many binders against different antigens and (3) describes 64 novel NA binding VHHs, including a broadly reactive $\mathrm{VHH}$, which can be used in various assays for influenza virus subtyping, detection or serology.
\end{abstract}


Keywords: recombinant neuraminidase; nanobody; single-domain antibody; phage display; enzymatic activity; antigenic site

\section{Introduction}

Avian influenza (AI) is a viral infection of poultry with a very different clinical picture, depending on the virus. Type A influenza viruses [1] are divided into subtypes based on differences in the antigenicity of two immunogenic surface proteins, hemagglutinin (HA) and neuraminidase (NA). The work described in this manuscript was performed before the recent discovery of a novel H17N10 subtype bat influenza A virus [2]. Since we focus on avian influenza, we still classify the type A viruses into sixteen HA (H1-H16) and nine NA (N1-N9) subtypes, as it was done until this recent novel subtype was discovered and which is still valid for avian influenza viruses. AI viruses of subtype $\mathrm{H} 5$ and $\mathrm{H} 7$ can evolve to viruses that cause very high mortality and, therefore, have devastating consequences for the poultry industry and trade. These so-called high-pathogenicity (HP) H5 and H7 viruses can also be transmitted to humans with high fatality among hospitalized individuals [3]. Therefore, in some regions, vaccination against H5 and H7 subtype influenza virus is used to control the disease in poultry. The FAO recommends that vaccination is performed with a vaccine that allows the Differentiation of Infected from Vaccinated Animals (DIVA). This can, among others, be accomplished by using inactivated vaccines produced using viruses of the $\mathrm{H} 5$ or $\mathrm{H} 7$ subtype combined with an $\mathrm{N}$ subtype that is different from that of the circulating outbreak virus [4]. For DIVA, a serological test is required that detects antibodies directed against the $\mathrm{N}$ type of the outbreak virus. Several monoclonal antibody (mAb)-based ELISAs for such serological detection of N1, N2 or N3 antibodies have been described [5-7]. However, suitable mAbs and ELISAs for detection of antibodies against (avian) N4-N9 are lacking.

NA cleaves sialic acid receptors from the cell surface, thereby releasing progeny viruses. It is a transmembrane protein with a large globular head that is composed of four identical subunits, whose tetramerization is essential for enzymatic activity. Inhibition of the NA enzyme activity by specific antibodies is used to determine the $\mathrm{N}$ subtype [8,9]. Most antigenic sites on NA are conformational. Inactivated virus vaccines generally generate the highest antibody response against HA and nucleoprotein (NP), which is located internally in the virion. Although HA and NA are equally immunogenic [10], the antibody response against NA is generally somewhat lower, because NA is present at reduced amounts as compared to HA and due to antigenic competition with HA. Thus, NA also contributes to vaccine efficacy, although to a lesser extent than HA [9,11]. As a result, there is also interest in measuring the NA content of influenza vaccines, preferably by ELISA [12]. Furthermore, due to the rapid antigenic variation of HA and NA, there is a need to update vaccines by using contemporarily circulating strains. This is currently done by antigenic cartography that is only based on HA by comparing the hemagglutination inhibition activities of panels of sera. Recently, it was demonstrated that antigenic drift, although to a lesser extent, also occurs in NA, affecting vaccine efficacy [13]. Thus, matching vaccine strains to viruses circulating in the field by using panels of antibodies against NA is also recommended [9]. 
We aimed to isolate mAbs against all $\mathrm{N}$ subtypes for use in serology during DIVA vaccination strategies and for use in control of NA quality and quantity of vaccines. For this purpose, we use llama single-domain antibody fragments (VHHs) as a source of mAbs [14,15]. VHHs are the small antigen binding domains derived from natural antibodies devoid of a light chain that occur in camelids [16]. They offer a number of advantages for biotechnological applications, such as a high production level in microorganisms and high physicochemical stability. Furthermore, due to their single gene nature, VHHs are highly suited for phage display selection of a diverse panel of antigen binding VHHs from immune libraries. VHHs can also be easily produced in multivalent formats to improve antigen binding affinity or potency by multivalent binding [17,18] or to construct bispecific recombinant antibodies that bind to two unrelated antigens [19]. Here, we describe the isolation and antigen binding in ELISA of a panel of VHHs that specifically bind the nine $\mathrm{N}$ subtypes, mostly in a subtype specific manner, but sometimes cross-reacting with other subtypes.

\section{Results and Discussion}

\subsection{Selections on Whole Virus Passively Adsorbed to Polystyrene}

Four llamas were immunized with mixtures of purified influenza viruses representing all (avian) $\mathrm{H}$ and $\mathrm{N}$ subtypes, and VHH phage display libraries were generated. The viruses used for immunization were preferably recent isolates from the Netherlands. Here, we only describe the isolation of NA binding VHHs. For the evaluation of selections, we performed parallel phage ELISA and phage display selection. Thus, phages were incubated with immobilized antigen at identical conditions in two wells, one of which was used for phage ELISA and the other for phage elution and transduction of Escherichia coli. After screening of binding of soluble VHH to antigens in ELISA, we identified 188 unique VHHs binding to the nine different $\mathrm{N}$ subtypes. The VHHs were classified according to subtype specificity. For each subtype, they were further classified into different complementarity determining region 3 (CDR3) groups based on their CDR3 sequence. VHHs of the same CDR3 group often contain similar VH coding regions, that belong to the same VHH subfamily [20]. They presumably arise from the same B-cell recombination process and most likely bind the same antigenic site. For further work, we preferentially selected clones from different CDR3 groups. We will only describe these 64 VHHs.

Initially, we aimed to enrich for NA binding phage by counter-selection of a HA binding phage using two sequential panning rounds on two viruses that have different H subtypes. Such a method was earlier successfully used to prevent enrichment of a phage that specifically binds to contaminating proteins present in antigen preparations [21]. However, a selection on H5N2 virus and, subsequently, on H6N2 or H9N2 virus yielded clones that bound to H5N2 virus, but not rN2 (Table 1). Note that this rN2 was derived from the same H5N2 virus later used for successful selection and screening of N2 binding clones (Table 4). This makes it unlikely that the binders selected are directed against NA. They are more likely directed against the immunologically conserved NP protein [22] or conserved epitopes of HA, possibly the stem region [23-25]. These binders may be more readily selected, because NP and HA are more immunogenic than NA [7,9]. 
Table 1. Phage display selection of N2 binding llama single-domain antibody fragments (VHHs) by alternating selection on $\mathrm{N} 2$ subtype strains. The second selection round was performed using a phage selected on $0.02 \mu \mathrm{g} / \mathrm{mL}$ of $\mathrm{H} 5 \mathrm{~N} 2$ virus. Viruses were always directly adsorbed to polystyrene plates. Clones were screened for binding to the indicated antigens by incubation with $E$. coli-produced soluble VHH.

\begin{tabular}{|c|c|c|c|c|c|c|}
\hline \multirow[b]{3}{*}{ Llama } & \multirow{2}{*}{\multicolumn{2}{|c|}{ First round selection }} & \multirow{2}{*}{\multicolumn{2}{|c|}{ Second round selection }} & \multicolumn{2}{|c|}{$\begin{array}{c}\text { No. of positive clones/ No. clones } \\
\text { screened }\end{array}$} \\
\hline & & & & & \multirow{2}{*}{$\begin{array}{c}1 \mu \mathrm{g} / \mathrm{mL} \text { H5N2 } \\
A_{450 \mathrm{~nm}}>1^{\mathrm{a}}\end{array}$} & \multirow{2}{*}{$\begin{array}{r}1.5 \mu \mathrm{g} / \mathrm{mL} \mathrm{rN2} \\
\mathrm{A}_{450 \mathrm{~nm}}>0.2^{\mathrm{a}}\end{array}$} \\
\hline & Antigen & $\mathbf{A}_{450 \mathrm{~nm}}$ & Antigen & $\mathbf{A}_{450 \mathrm{~nm}}$ & & \\
\hline 3049 & $2 \mu \mathrm{g} / \mathrm{mL} \mathrm{H} 5 \mathrm{~N} 2$ & 0.827 & & & & \\
\hline 3049 & $0.2 \mu \mathrm{g} / \mathrm{mL} \mathrm{H} 5 \mathrm{~N} 2$ & 0.851 & & & & \\
\hline \multirow[t]{5}{*}{3049} & $0.02 \mu \mathrm{g} / \mathrm{mL} \mathrm{H} 5 \mathrm{~N} 2$ & 0.775 & $0.1 \mu \mathrm{g} / \mathrm{mL}$ H6N2 & 1.828 & $7 / 13$ & $0 / 13$ \\
\hline & & & $0.01 \mu \mathrm{g} / \mathrm{mL}$ H6N2 & 1.112 & $7 / 16$ & $0 / 16$ \\
\hline & & & Without antigen & 0.074 & & \\
\hline & & & $0.1 \mu \mathrm{g} / \mathrm{mL} \mathrm{H} 9 \mathrm{~N} 2$ & 1.819 & $6 / 16$ & $0 / 16$ \\
\hline & & & $0.01 \mu \mathrm{g} / \mathrm{mL}$ H9N2 & 1.892 & $6 / 16$ & $0 / 16$ \\
\hline 3049 & Without antigen & 0.051 & & & & \\
\hline
\end{tabular}

${ }^{\mathrm{a}}$ The absorbance value at which clones were scored positive.

We next tried to enrich for NA binding phages during panning on low concentrations of immobilized virus by competition with a high concentration of soluble virus of the same $\mathrm{H}$ subtype, but a different $\mathrm{N}$ subtype. This should result in reduced recovery of the phage displaying HA and NP binding VHHs. Thus, selections on H7N1 were competed with H7N7 virus and vice versa. As compared to control selections without competition that were performed in parallel, selections with competition resulted in 3-4-fold lower absorbance values in both the first and second selection round, while absorbance values remained above the background without antigen (Table 2). This suggests that competition was at least partially successful. However, when individual clones were screened for binding of soluble $\mathrm{VHH}$ to $\mathrm{H} 7 \mathrm{~N} 1$ or $\mathrm{H} 7 \mathrm{~N} 7$ virus, all binders gave comparable absorbance values on both viruses (Table 2), suggesting binding to H7 or NP. Thus, competition with soluble influenza virus did not stimulate enrichment of NA binding VHHs. These results are consistent with other reports that have indicated that pre-clearing during phage display selection is often of limited usefulness $[21,26]$.

Table 2. Phage display selection of N1 or N7 binding VHHs by competition with other viruses. Phage libraries were first incubated with or without a high concentration of soluble H7N7 or H7N1 virus and, subsequently, selected using low concentrations of immobilized, H7N1 or H7N7 virus, respectively. Clones were screened for binding to immobilized H7N1 and H7N7 virus by incubation with E. coli-produced soluble VHH.

\begin{tabular}{|c|c|c|c|c|c|c|c|c|c|}
\hline \multirow[b]{4}{*}{ Llama } & \multicolumn{3}{|c|}{ First round selection } & \multicolumn{3}{|c|}{ Second round selection } & \multirow{2}{*}{\multicolumn{3}{|c|}{$\begin{array}{c}\text { No. of clones with } \mathrm{A}_{450 \mathrm{~nm}}>1 / \mathrm{No} \\
\text { clones screened }^{\mathrm{a}}\end{array}$}} \\
\hline & \multirow{2}{*}{\multicolumn{3}{|c|}{$\begin{array}{c}\text { A450 nm with or } \\
\text { without } \\
\text { competing virus } \\
\end{array}$}} & \multirow[b]{3}{*}{ Antigen } & \multirow{2}{*}{\multicolumn{2}{|c|}{$\begin{array}{c}\mathbf{A}_{450 \mathrm{~nm}} \text { with or } \\
\text { without competing } \\
\text { virus } \\
\end{array}$}} & & & \\
\hline & & & & & & & $\begin{array}{c}5 \mu \mathrm{g} / \mathrm{mL} \\
\mathrm{H} 7 \mathrm{N1}\end{array}$ & $\begin{array}{c}5 \\
\mu \mathrm{g} / \mathrm{mL}\end{array}$ & $\begin{array}{l}\text { H7N1 } \\
\text { and }\end{array}$ \\
\hline & Antigen & without & with & & without & with & & H7N7 & H7N7 \\
\hline 3049 & $2 \mu \mathrm{g} / \mathrm{mL} \mathrm{H} 7 \mathrm{~N} 1$ & 0.662 & 0.313 & & & & & & \\
\hline 3049 & $0.2 \mu \mathrm{g} / \mathrm{mL} \mathrm{H7N1}$ & 0.701 & 0.278 & & & & & & \\
\hline
\end{tabular}


Table 2. Cont.

\begin{tabular}{|c|c|c|c|c|c|c|c|c|c|}
\hline \multirow[b]{4}{*}{ Llama } & \multicolumn{3}{|c|}{ First round selection } & \multicolumn{3}{|c|}{ Second round selection } & \multirow{2}{*}{\multicolumn{3}{|c|}{$\begin{array}{c}\text { No. of clones with } \mathbf{A}_{450 \mathrm{~nm}}>1 / \mathrm{No} \\
\text { clones screened }^{\text {a }}\end{array}$}} \\
\hline & \multirow[b]{3}{*}{ Antigen } & \multirow{2}{*}{\multicolumn{2}{|c|}{$\begin{array}{c}A_{450} \mathrm{~nm} \text { with or } \\
\text { without competing } \\
\text { virus } \\
\end{array}$}} & \multirow[b]{3}{*}{ Antigen } & \multirow{2}{*}{\multicolumn{2}{|c|}{$\begin{array}{c}A_{450 \mathrm{~nm}} \text { with or } \\
\text { without competing } \\
\text { virus } \\
\end{array}$}} & & & \\
\hline & & & & & & & $\begin{array}{c}5 \mu \mathrm{g} / \mathrm{mL} \\
\mathrm{H} 7 \mathrm{N1}\end{array}$ & $\begin{array}{c}5 \\
\mu \mathrm{g} / \mathrm{mL}\end{array}$ & $\begin{array}{l}\text { H7N1 } \\
\text { and }\end{array}$ \\
\hline & & without & with & & without & with & & H7N7 & H7N7 \\
\hline \multirow[t]{5}{*}{3049} & $0.02 \mu \mathrm{g} / \mathrm{mL}$ & 0.490 & 0.152 & $0.1 \mu \mathrm{g} / \mathrm{mL}$ & 0.426 & 0.306 & $6 / 16$ & $6 / 16$ & $6 / 16$ \\
\hline & H7N1 & & & H7N1 & & & & & \\
\hline & & & & $0.01 \mu \mathrm{g} / \mathrm{mL}$ & 0.362 & 0.219 & $6 / 16$ & $5 / 16$ & $5 / 16$ \\
\hline & & & & H7N1 & & & & & \\
\hline & & & & Without antigen & 0.088 & 0.077 & & & \\
\hline 3049 & $2 \mu \mathrm{g} / \mathrm{mL}$ H7N7 & 0.516 & 0.142 & & & & & & \\
\hline \multirow[t]{5}{*}{3049} & $0.2 \mu \mathrm{g} / \mathrm{mL}$ & 0.674 & 0.161 & $0.1 \mu \mathrm{g} / \mathrm{mL}$ & 0.450 & 0.141 & $7 / 13$ & $6 / 13$ & $6 / 13$ \\
\hline & H7N7 & & & H7N7 & & & & & \\
\hline & & & & $0.01 \mu \mathrm{g} / \mathrm{mL}$ & 0.294 & 0.091 & $6 / 16$ & $5 / 16$ & $5 / 16$ \\
\hline & & & & H7N7 & & & & & \\
\hline & & & & Without antigen & 0.099 & 0.082 & & & \\
\hline 3049 & $\begin{array}{c}0.02 \mu \mathrm{g} / \mathrm{mL} \\
\text { H7N7 }\end{array}$ & 0.428 & 0.094 & & & & & & \\
\hline 3049 & $\begin{array}{l}\text { Without } \\
\text { antigen }\end{array}$ & 0.052 & 0.057 & & & & & & \\
\hline
\end{tabular}

${ }^{a}$ The number of clones positive (absorbance value $>1$ ) out of the number of clones screened is indicated. The number of clones positive on both $\mathrm{H} 7 \mathrm{~N} 1$ and $\mathrm{H} 7 \mathrm{~N} 7$ virus is also indicated.

\subsection{Selections on Recombinant NA}

For use in phage display selection, we prepared recombinant NA (rNA) consisting of the soluble head domain of different N subtypes by expression in HEK293 cells (Table 3). Some rNA preparations were derived from different virus strains than those used for llama immunization. Expression of rN6 was not successful, but rNA of the further eight subtypes could be produced and purified. The specific enzymatic activity of the different preparations varied considerably. We could not detect enzymatic activity of rN1, rN4 and rN5 (Table 3), suggesting that these rNAs were produced in a misfolded form, which could be due to either an incorrect tertiary structure or lack of tetramerization.

The eight rNA preparations were used in phage display selections after direct passive adsorption to polystyrene. The three inactive rNA preparations gave the lowest $(<0.171)$ absorbance value in phage ELISA after the first selection round (Table 3). This could be due to misfolding of these inactive rNA preparations, since most antigenic sites on NA are conformational [9]. A correlation between enzymatic activity and antigenicity of virus-derived NA was earlier reported [27]. In the case of rN1 and $\mathrm{rN5}$, but not of $\mathrm{rN} 4$, it could also be due to the different viruses that the rNA was derived from and the antigen used for llama immunization. The five enzymatically active rNA preparations gave higher absorbance values in phage ELISA (0.359 to 1.619), suggesting that selections were more efficient. Eventually, we performed two rounds of phage display selection using rNA in round one and whole virus or rNA in the second round. Soluble VHH of individual clones was screened for binding to rNA and viruses with different $\mathrm{N}$ subtypes to determine their subtype specificity. Especially after selection on enzymatically inactive rNA, clones that bound whole virus often did not react with rNA. This 
suggests that these clones are NA specific, but do not bind inactive rNA, because of its presumed misfolding. VHHs against rN1, rN4 and rN5 were, therefore, often not analyzed for binding to rNA in later experiments (Table 4).

Such selections on rN2, rN3, rN4, rN7, rN8 and rN9 were highly efficient and resulted in diverse panels of binders, representing at least three CDR3 groups that specifically bound NA (Table 4). Selection on rN1 similarly yielded binders representing three CDR3 groups. However, selection on rN5 yielded only one binder (IV224), possibly due to the misfolding or heterologous nature of rN5. Furthermore, selections on rN6 could not be done, because it was not available.

Table 3. Recombinant neuraminidase (NA) proteins used.

\begin{tabular}{|c|c|c|c|c|c|c|c|}
\hline \multirow[t]{2}{*}{ NA } & \multirow[t]{2}{*}{ Strain origin } & \multirow[t]{2}{*}{ Subtype } & \multirow[t]{2}{*}{$\begin{array}{c}\text { EMBL } \\
\text { accession no. }\end{array}$} & \multirow[t]{2}{*}{$\begin{array}{l}\text { Amino } \\
\text { acids }\end{array}$} & \multirow[t]{2}{*}{$\begin{array}{c}\text { Specific NA } \\
\text { enzyme activity } \\
(\mu \mathrm{mol} / \mathrm{mg} / \mathrm{min})^{\mathrm{a}}\end{array}$} & \multicolumn{2}{|c|}{$\begin{array}{c}\text { Phage display } \\
\text { selection on } 1 \\
\mu \mathrm{g} / \mathrm{mL} \text { rNA }\end{array}$} \\
\hline & & & & & & Llama $^{\mathrm{c}}$ & $\mathbf{A}_{450 \mathrm{~nm}}$ \\
\hline rN1 & A/turkey/Turkey/1/2005 & $\mathrm{H} 5 \mathrm{~N} 1$ & EF619973 & $55-449$ & $<0.08$ & 3049 & 0.171 \\
\hline $\mathrm{rN} 2$ & $\mathrm{~A} / \mathrm{mallard} / \mathrm{Neth} / 2 / 2005$ & $\mathrm{H} 5 \mathrm{~N} 2$ & CY041252 & $75-469$ & 1.45 & $\underline{3049}$ & 0.474 \\
\hline rN3 & A/ostrich/Neth/03006814/2003 & $\mathrm{H} 2 \mathrm{~N} 3$ & CY122198 & $75-469$ & 4.21 & $\underline{3050}$ & 1.568 \\
\hline $\mathrm{rN} 4$ & A/mallard/Neth/06026212-002/2006 & H8N4 & CY043850 & $74-470$ & $<0.08$ & $\underline{3050}$ & 0.094 \\
\hline rN5 & A/turkey/Neth/07014290/2007 & H1N5 & None & $55-449$ & $<0.08$ & 3050 & 0.076 \\
\hline rN6 & A/mallard/Norway/10_1334/2006 & H4N6 & FM179763 & $75-470$ & $\mathrm{ND}^{\mathrm{b}}$ & ND & ND \\
\hline rN7 & A/chicken/Neth/03010132/2003 & H7N7 & EF015553 & $74-471$ & 0.32 & 3049 & 1.619 \\
\hline rN8 & A/Bewick's swan/Neth/2/2005 & H6N8 & DQ822200 & $73-470$ & 0.18 & 3050 & 0.928 \\
\hline rN9 & A/shoveler/Neth/19/1999 & H11N9 & CY005853 & $76-470$ & 0.7 & 3050 & 0.359 \\
\hline
\end{tabular}

\subsection{Selections on Viral NA by Immunocapture with VHHs}

The VHHs isolated thus far were used as tools for specific capture of virus NA of particular strains in novel selections. For this purpose, the E. coli-produced VHHs (suffix Y) were coated onto polystyrene plates and then incubated with virus that was treated with Triton X-100. Such a detergent treatment solubilizes the viral membrane, resulting in the release of the viral surface proteins into solution. Due to the use of a specific VHH as the capture antibody, NA is immobilized on the plate used for phage display selection, whereas the other viral proteins, especially HA and NP, are washed away. This enables to use the same strain for llama immunization and selection. Thus, we used the N5 binder IV224Y for the capture of H1N5 virus NA to select novel N5 binders from two llamas immunized with either H1N5 and H12N5 virus or with H6N5 virus. Similarly, the N1 binder, IV176Y, was used for the capture of H7N1 virus NA to select novel N1 binders (Table 4).

Some isolated VHHs were found to cross-react with several other NAs. For example, the N7 binder IV237Y cross-reacts with N6 subtype virus (results not shown for IV237Y; however, see Tables 5 and 6 for yeast-produced IV237F). IV237Y is a genuine NA binder, since it binds to rN7, although with a low absorbance value (Table 4). We used IV237Y for the capture of H14N6 or H13N6 virus to select N6 binding VHHs. This resulted in five binders of different CDR3 groups. Similarly, IV457F, 
resulting from selections on $\mathrm{rN} 4$, cross-reacted with other $\mathrm{N}$ subtypes with the highest absorbance value on the H14N6 virus (Table 5) and was therefore classified as an N6 binder. Most clones isolated thus far had significantly higher absorbance values on H14N6 than on H13N6 virus. Yeast-produced N6 binders IV457F and IV461F were therefore used for the capture of H13N6 virus in novel rounds of phage display selection, resulting in five novel binders representing three novel CDR3 groups. Four of these novel binders bound well to H13N6 virus.

Another two clones, IV235 and IV456, within the same CDR3 group (Table 4), were initially selected using N6 or N7 subtype virus, but were later found to be specific for N3 viruses. IV456F was then used for the capture of solubilized H2N3 virus and selection of a single VHH (IV540) from a llama immunized with $\mathrm{H} 16 \mathrm{~N} 3$ virus. This $\mathrm{VHH}$ bound inefficiently $\left(\mathrm{A}_{450 \mathrm{~nm}}=0.098\right.$; Table 4 ) to directly coated $\mathrm{H} 2 \mathrm{~N} 3$ virus, but much better $\left(\mathrm{A}_{450 \mathrm{~nm}}=0.521\right)$ to Triton $\mathrm{X}-100$ treated $\mathrm{H} 2 \mathrm{~N} 3$ virus captured with IV456F. This suggests that this clone recognizes an antigenic site that is better accessible, due to either surfactant disruption of virions or the capture of the NA in solution with a $\mathrm{VHH}$.

We also selected three novel N9 binding VHHs representing three novel CDR3 groups using solubilized H15N9 virus captured with N9 binder, IV295F.

\subsection{Yeast Expression of VHHs}

We selected 64 different VHHs that preferentially belong to different CDR3 groups for expression in baker's yeast. These VHHs were inserted into episomal plasmid, pRL188, which is suitable for production of VHHs fused to the llama heavy-chain antibody long hinge region and contains a single C-terminal cysteine, as indicated by the suffix, F. Some VHHs were expressed at a higher yield by the transfer of the expression cassette from the pRL188-derived plasmid into a MIRY-type vector (Table 4). The yeast-produced VHHs were purified by immobilized-metal affinity chromatography (IMAC). Five VHHs (Table 4) contain a potential N-glycosylation site. These VHHs were treated with endoglycosidase $\mathrm{H}$ or mock-treated and then analyzed by reducing SDS-PAGE. Unglycosylated or deglycosylated VHH migrates at about $20 \mathrm{kDa}$, whereas glycosylated VHH migrates much slower. From such an analysis (Figure 1), we conclude that IV84F is not glycosylated, IV202F and IV456F are partially (about 50\%) hyperglycosylated, IV81F is predominantly hyperglycosylated and IV467F is predominantly core-like glycosylated. In subsequent analysis, we always used endoglycosidase-H-treated preparations of the four glycosylated VHHs.

\subsection{NA Specificity of Yeast-Produced VHHs}

All 64 VHHs were analyzed in ELISA for binding to influenza viruses representing all N subtypes (Table 5) to assess their cross-reaction with different $\mathrm{N}$ subtypes. A subset of 41 of these VHHs was biotinylated and again analyzed for binding to different influenza viruses in ELISA (Table 6). The ELISA is much more sensitive when using biotinylated VHH and a streptavidin-peroxidase conjugate than when using non-biotinylated VHH that is detected based on its his6 tag. Some clones, such as IV417F (N1), IV105F (N2) and IV75F (N2), yield high absorbance values when biotinylated, but show no absorbance value above the background using non-biotinylated VHH. 
Table 4. Phage display selection history, antigen binding in ELISA and sequence characteristics of VHH clones selected for yeast expression.

\begin{tabular}{|c|c|c|c|c|c|c|c|c|c|c|c|c|c|}
\hline \multirow{3}{*}{$\begin{array}{l}\text { N } \\
\text { Sub- } \\
\text { type }\end{array}$} & \multirow{3}{*}{$\begin{array}{l}\text { VHH } \\
\text { Clone }\end{array}$} & \multirow[b]{3}{*}{ Llama } & \multirow{3}{*}{$\begin{array}{l}\text { Phage Display Selection }{ }^{\text {a }} \\
\text { (round 1/ round 2) }\end{array}$} & \multicolumn{5}{|c|}{ ELISA signal with influenza viruses ${ }^{\text {b }}$} & \multirow{3}{*}{$\begin{array}{l}\text { Potential } \\
\text { N-glyco- } \\
\text { sylation } \\
\text { Site }^{c}\end{array}$} & \multirow{3}{*}{$\begin{array}{l}\text { VHH } \\
\text { Sub- } \\
\text { Family' }\end{array}$} & \multirow{2}{*}{\multicolumn{2}{|c|}{ CDR3 }} & \multirow{3}{*}{$\begin{array}{l}\text { Yeast } \\
\text { Expres- } \\
\text { sion }^{\mathrm{f}}\end{array}$} \\
\hline & & & & \multicolumn{2}{|c|}{$\begin{array}{c}\text { Influenza } \\
\text { Virus }\end{array}$} & \multicolumn{2}{|c|}{$\begin{array}{c}\text { Influenza } \\
\text { Virus }\end{array}$} & \multirow{2}{*}{$\begin{array}{l}\text { Homo- } \\
\text { logous } \\
\text { rNA }\end{array}$} & & & & & \\
\hline & & & & Subtype & $\mathbf{A}_{450 \mathrm{~nm}}$ & Subtype & $\mathbf{A}_{450 \mathrm{~nm}}$ & & & & Sequence & Group $^{\mathrm{e}}$ & \\
\hline 1 & IV169 & 3049 & $\mathrm{rN} 1 / \mathrm{rN} 1$ & $\mathrm{H} 1 \mathrm{~N} 1$ & 0.069 & $\mathrm{H} 7 \mathrm{~N} 1$ & 0.550 & ND & None & $\mathrm{C}$ & ILGGRGIMDPRERQ & A & MIRY \\
\hline 1 & IV403 & 3049 & $\mathrm{rN} 1 / \mathrm{rN} 1$ & H1N1 & 0.308 & $\mathrm{H} 7 \mathrm{~N} 1$ & 0.680 & ND & None & $\mathrm{C}$ & RIGGREIMDSRERQ & A & MIRY \\
\hline 1 & IV417 & 3049 & rN1/IV176Y H7N1 & H1N1 & 0.079 & $\mathrm{H} 7 \mathrm{~N} 1$ & 0.583 & ND & None & 1 & AASSLSGARSRPGDYDY & B & MIRY \\
\hline 1 & IV171 & 3049 & $\mathrm{rN} 1 / \mathrm{rN} 1$ & H1N1 & 0.060 & $\mathrm{H} 7 \mathrm{~N} 1$ & 0.358 & ND & None & 1 & AADRYWNPVSWDY & $\mathrm{C}$ & MIRY \\
\hline 1 & IV176 & 3049 & $\mathrm{rN} 1 / \mathrm{H} 1 \mathrm{~N} 1$ & H1N1 & 0.086 & $\mathrm{H} 7 \mathrm{~N} 1$ & 0.673 & ND & None & 3 & AASKYGSCNGGTNENDY & $\mathrm{D}$ & Not done \\
\hline 1 & IV414 & 3049 & rN1/IV176Y H7N1 & H1N1 & 0.130 & H7N1 & 0.476 & ND & None & 1 & AASERALLRLATSQWDYNY & E & MIRY \\
\hline 1 & IV426 & 3049 & IV176Y H7N1/rN1 ${ }^{\mathrm{ST}}$ & H1N1 & 0.081 & $\mathrm{H} 7 \mathrm{~N} 1$ & 0.571 & ND & None & 1 & AASQRSLPLNFLSQYDYDY & $\mathrm{F}$ & Episomal \\
\hline 1 & IV422 & 3049 & $\mathrm{rN1} 1^{\mathrm{ST}} / \mathrm{IV} 176 \mathrm{Y}$ H7N1 & H1N1 & 0.077 & $\mathrm{H} 7 \mathrm{~N} 1$ & 0.751 & ND & None & 3 & ATDWYCSDSAELSDFTS & G & MIRY \\
\hline 2 & IV 63 & 3049 & $\mathrm{rN} 2 / \mathrm{rN} 2$ & $\mathrm{H} 5 \mathrm{~N} 2$ & 0.195 & $\mathrm{ND}$ & & 1.904 & None & 1 & AADPNGRGYYY & $\mathrm{A}$ & Episomal \\
\hline 2 & IV82 & 3049 & $\mathrm{rN} 2 / \mathrm{rN} 2$ & $\mathrm{H} 5 \mathrm{~N} 2$ & 0.113 & ND & & 1.277 & None & 1 & AADPNGRGYYY & A & Episomal \\
\hline 2 & IV104 & 3049 & $\mathrm{rN} 2 / \mathrm{rN} 2$ & $\mathrm{H} 5 \mathrm{~N} 2$ & 0.180 & ND & & 1.801 & None & 1 & AADPNGRGYYY & A & Episomal \\
\hline 2 & IV65 & 3049 & $\mathrm{rN} 2 / \mathrm{rN} 2$ & $\mathrm{H} 5 \mathrm{~N} 2$ & 0.068 & ND & & 1.019 & None & 1 & AADRSSLQLYASRVGYDY & B & Episomal \\
\hline 2 & IV77 & 3049 & $\mathrm{rN} 2 / \mathrm{rN} 2$ & $\mathrm{H} 5 \mathrm{~N} 2$ & 0.168 & ND & & 1.651 & None & 1 & AASYFWSDTPFALNYRY & $\mathrm{C}$ & Episomal \\
\hline 2 & IV105 & 3049 & $\mathrm{rN} 2 / \mathrm{rN} 2$ & $\mathrm{H} 5 \mathrm{~N} 2$ & 0.060 & ND & & 1.91 & None & 1 & AGDRDGRGYVY & $\mathrm{D}$ & Episomal \\
\hline 2 & IV75 & 3049 & $\mathrm{rN} 2 / \mathrm{rN} 2$ & $\mathrm{H} 5 \mathrm{~N} 2$ & 0.059 & ND & & 1.826 & None & $\mathrm{X}$ & AAAVGSRWYEL & E & Episomal \\
\hline 2 & IV78 & 3049 & $\mathrm{rN} 2 / \mathrm{rN} 2$ & $\mathrm{H} 5 \mathrm{~N} 2$ & 0.088 & ND & & 1.306 & None & 3 & AATPIADASNYCSDYQDFMHY & $\mathrm{F}$ & Episomal \\
\hline 2 & IV95 & 3049 & $\mathrm{rN} 2 / \mathrm{rN} 2$ & $\mathrm{H} 5 \mathrm{~N} 2$ & 0.202 & ND & & 1.796 & None & 1 & AAEILYCSGYGCRDPRLYNY & G & Episomal \\
\hline 2 & IV97 & 3049 & $\mathrm{rN} 2 / \mathrm{rN} 2$ & $\mathrm{H} 5 \mathrm{~N} 2$ & 0.120 & ND & & 1.885 & None & 1 & SASTLLPTNDY & $\mathrm{H}$ & Episomal \\
\hline 2 & IV107 & 3049 & $\mathrm{rN} 2 / \mathrm{rN} 2$ & $\mathrm{H} 5 \mathrm{~N} 2$ & 0.120 & ND & & 1.759 & None & 1 & AAGFITGIHPYEYHY & I & Episomal \\
\hline 2 & IV81 & 3049 & $\mathrm{rN} 2 / \mathrm{rN} 2$ & $\mathrm{H} 5 \mathrm{~N} 2$ & 0.242 & ND & & 1.842 & 57 & 1 & AASQWDGRTWTRPHAYEY & $\mathrm{J}$ & Episomal \\
\hline 2 & IV84 & 3049 & $\mathrm{rN} 2 / \mathrm{rN} 2$ & $\mathrm{H} 5 \mathrm{~N} 2$ & 0.145 & ND & & 1.81 & 57,61 & 1 & AADLGAYGGLGLSYDY & $\mathrm{K}$ & Episomal \\
\hline 3 & IV 185 & 3050 & $\mathrm{rN} 3^{\mathrm{ST}} / \mathrm{H} 2 \mathrm{~N} 3$ & $\mathrm{H} 2 \mathrm{~N} 3$ & 0.691 & $\mathrm{H} 16 \mathrm{~N} 3$ & 0.060 & 1.134 & None & 3 & ASIKMYRNSWSGCSALDYYGMDY & $\bar{A}$ & MIRY \\
\hline 3 & IV191 & 3050 & $\mathrm{rN} 3 / \mathrm{rN} 3$ & $\mathrm{H} 2 \mathrm{~N} 3$ & 0.461 & $\mathrm{H} 16 \mathrm{~N} 3$ & 0.062 & 1.157 & None & 3 & ASIIIHTRSWSGCSALDYYGMDY & A & MIRY \\
\hline 3 & IV235 & 3049 & $\mathrm{rN} 7 / \mathrm{rN} 7$ & $\mathrm{H} 2 \mathrm{~N} 3$ & 0.054 & $\mathrm{H} 16 \mathrm{~N} 3$ & 0.052 & ND & None & 2 & NAEEDPLYGGRRGRNY & B & MIRY \\
\hline 3 & IV456 & 3050 & IV297Y H13N6/IV297Y H13N6 & $\mathrm{H} 2 \mathrm{~N} 3$ & 1.182 & $\mathrm{H} 16 \mathrm{~N} 3$ & 0.164 & ND & 59 & 2 & NADEDPYYGGRRGRNY & B & MIRY \\
\hline 3 & IV187 & 3050 & $\mathrm{rN}^{\mathrm{ST}} / \mathrm{H} 2 \mathrm{~N} 3$ & $\mathrm{H} 2 \mathrm{~N} 3$ & 0.529 & H16N3 & 0.055 & 0.638 & None & 2 & AADTYYSRGYDF & $\mathrm{C}$ & MIRY \\
\hline 3 & IV202 & 3050 & rN3/H2N3 & $\mathrm{H} 2 \mathrm{~N} 3$ & 0.554 & $\mathrm{H} 16 \mathrm{~N} 3$ & 0.061 & 0.382 & 60 & 3 & AADSNVGSMCRDMYADLDV & $\mathrm{D}$ & MIRY \\
\hline 3 & IV 540 & 3467 & IV456F H2N3/IV237F H2N3 & $\mathrm{H} 2 \mathrm{~N} 3$ & 0.098 & $\mathrm{H} 16 \mathrm{~N} 3$ & 0.058 & ND & None & $\mathrm{X}$ & KAAWSTL & E & Episomal \\
\hline 4 & IV 207 & 3049 & $\mathrm{rN} 4 / \mathrm{H} 8 \mathrm{~N} 4$ & $\mathrm{H} 8 \mathrm{~N} 4$ & 0.268 & ND & & 0.135 & None & 2 & NAASFHAMGRDDY & A & MIRY \\
\hline 4 & IV215 & 3049 & $\mathrm{rN} 4 / \mathrm{rN} 4$ & H8N4 & 0.333 & ND & & ND & None & 2 & NAASFHAMGRDDY & A & MIRY \\
\hline 4 & IV213 & 3049 & $\mathrm{rN} 4 / \mathrm{rN} 4$ & H8N4 & 0.578 & ND & & ND & None & 2 & HAEGYYSDSGRGAWRDY & B & MIRY \\
\hline 4 & IV297 & 3049 & $\mathrm{rN} 4 / \mathrm{rN} 4$ & H8N4 & 0.215 & ND & & ND & None & 2 & HAEGYYSDSGRGAWRDY & B & MIRY \\
\hline 4 & IV208 & 3049 & $\mathrm{rN} 4 / \mathrm{rN} 4$ & $\mathrm{H} 8 \mathrm{~N} 4$ & 0.115 & ND & & ND & None & 2 & NAPWRPRGLD & C & MIRY \\
\hline 5 & IV 224 & 3050 & $\mathrm{rN} 5 / \mathrm{H} 1 \mathrm{~N} 5$ & H1N5 & 0.111 & H6N5 & ND & ND & None & $\mathrm{C}$ & EKLIDSSGFYSADY & $\mathrm{A}$ & MIRY \\
\hline 5 & IV451 & 3466 & IV224Y H1N5/IV224Y H1N5 & H1N5 & 0.222 & H6N5 & 0.115 & ND & None & 1 & AAHRTRYGLGVSAADFGS & B & MIRY \\
\hline 5 & IV442 & 3466 & IV224Y H1N5/IV224Y H1N5 & H1N5 & 0.344 & H6N5 & 0.119 & ND & None & $\mathrm{C}$ & ERGSWRSSDW & $\mathrm{C}$ & MIRY \\
\hline 5 & IV447. & 3050 & IV224Y H1N5/IV224Y H1N5 & H1N5 & 0.071 & H6N5 & 0.129 & ND & None & C & AKNTVSRLYGPYNE & D & MIRY \\
\hline$\ddot{6}$ & IV 501 & 3467 & IV457F H13N6/IV457F H13N6 & $\mathrm{H} 13 \mathrm{~N} 6$ & 0.358 & $\mathrm{H} 14 \mathrm{~N} 6$ & 0.078 & $\mathrm{ND}$ & None & 1 & AARTTMPNEVAPHYGMDY & $\mathrm{A}^{-}$ & Episomal \\
\hline 6 & IV457 & 3467 & $\mathrm{rN} 4 / \mathrm{rN}^{\mathrm{ST}}$ & H13N6 & 0.153 & H14N6 & 0.977 & ND & None & 1 & AVGFEAGYDY & B & MIRY \\
\hline
\end{tabular}


Table 4. Cont.

\begin{tabular}{|c|c|c|c|c|c|c|c|c|c|c|c|c|c|}
\hline \multirow{3}{*}{$\begin{array}{l}\text { N } \\
\text { Sub- } \\
\text { type }\end{array}$} & \multirow{3}{*}{$\begin{array}{l}\text { VHH } \\
\text { Clone }\end{array}$} & \multirow[b]{3}{*}{ Llama } & \multirow{3}{*}{$\begin{array}{l}\text { Phage Display Selection a } \\
\text { (round } 1 / \text { round } 2 \text { ) }\end{array}$} & \multicolumn{5}{|c|}{ ELISA signal with influenza viruses ${ }^{b}$} & \multirow{3}{*}{$\begin{array}{l}\text { Potential } \\
\text { N-glyco- } \\
\text { sylation } \\
\text { Site }^{c}\end{array}$} & \multirow{3}{*}{$\begin{array}{l}\text { VHH } \\
\text { Sub- } \\
\text { Family }\end{array}$} & \multirow{3}{*}{ Sequence } & \multirow[b]{3}{*}{ Group $^{\mathrm{e}}$} & \multirow{3}{*}{$\begin{array}{l}\text { Yeast } \\
\text { Expres- } \\
\text { Sion }^{\mathrm{f}} \\
\end{array}$} \\
\hline & & & & \multicolumn{2}{|c|}{$\begin{array}{c}\text { Influenza } \\
\text { Virus }\end{array}$} & \multicolumn{2}{|c|}{$\begin{array}{l}\text { Influenza } \\
\text { Virus }\end{array}$} & \multirow{2}{*}{$\begin{array}{l}\text { Homo- } \\
\text { logous } \\
\text { rNA } \\
\end{array}$} & & & & & \\
\hline & & & & Subtype & $\mathbf{A}_{450 \mathrm{~nm}}$ & Subtype & $\mathbf{A}_{450 \mathrm{~nm}}$ & & & & & & \\
\hline 6 & IV512 & 3467 & IV457F H13N6 / IV457F H13N6 & H13N6 & 0.675 & H14N6 & 0.758 & ND & None & 2 & NFRDYYYSELGEDY & $\mathrm{C}$ & Episomal \\
\hline 6 & IV618 & 3467 & IV237Y H14N6/H14N6 & H13N6 & 0.220 & H14N6 & 0.300 & ND & None & 2 & NFRDYYYSELGEDY & $\mathrm{C}$ & Episomal \\
\hline 6 & IV461 & 3467 & IV237Y H14N6/IV237Y H14N6 & H13N6 & 0.070 & H14N6 & 0.276 & ND & None & 1 & GVGPYGSRWHHDFGS & $\mathrm{D}$ & MIRY \\
\hline 6 & IV462 & 3467 & IV237Y H14N6/IV237Y H14N6 & H13N6 & 0.066 & H14N6 & 0.191 & ND & None & 1 & ALSQYGLAKVENAYDS & E & Episomal \\
\hline 6 & IV467 & 3467 & IV237Y H13N6/IV237Y H13N6 & H13N6 & 0.089 & H14N6 & 0.720 & ND & 20,93 & 1 & AGKASTYLDYGLYWTANSYTN & F & Episomal \\
\hline 6 & IV513 & 3467 & IV457F 1H13N6/IV457F H13N6 & H13N6 & 0.591 & H14N6 & 0.678 & ND & None & 3 & AAKWTDLSTWWDAGAMDY & G & Episomal \\
\hline 6 & IV514 & 3467 & IV457F H13N6/IV457F H13N6 & H13N6 & 0.449 & H14N6 & 0.560 & ND & None & 1 & AADPGFNSYYSEVGLYDY & $\mathrm{H}$ & Episomal \\
\hline 6 & IV619 & 3467 & IV237Y H14N6/H14N6 & H13N6 & 0.174 & H14N6 & 0.245 & ND & None & 1 & AADPGFNSYYNEVGLYDY & $\mathrm{H}$ & Episomal \\
\hline 6. & IV516. & 3467 & IV461F $1 \mathrm{H} 13 \mathrm{~N} 6 / \mathrm{IV} 461 \mathrm{~F}$ H13N6. & H13N6. & 0.126. & H14N6. & 0.595 & ND. & None. & 1. & AADAHAYYSGSYFNHGQLEGAAMDY & I & Episomal . \\
\hline 7 & IV 246 & 3049 & $\mathrm{rN} 7 / \mathrm{H} 7 \mathrm{~N} 7$ & $\mathrm{H} 5 \mathrm{~N} 7$ & 0.655 & $\mathrm{H} 7 \mathrm{~N} 7$ & 1.115 & 0.09 & None & 1 & ATTQTSGSMLEGYYGF & $\mathrm{A}$ & MIRY \\
\hline 7 & IV252 & 3049 & $\mathrm{H} 5 \mathrm{~N} 7 \mathrm{cH} 5 \mathrm{~N} 2 / \mathrm{rN} 7$ & H5N7 & 0.579 & H7N7 & 1.074 & 0.139 & None & 1 & ATTQSSGAKSEAYYGF & A & MIRY \\
\hline 7 & IV242 & 3049 & $\mathrm{rN} 7 / \mathrm{H} 5 \mathrm{~N} 7$ & $\mathrm{H} 5 \mathrm{~N} 7$ & 0.224 & H7N7 & 0.396 & 0.094 & None & 1 & AVHYSGTYSDPNSYGH & B & Episomal \\
\hline 7 & IV237 & 3049 & $\mathrm{rN} 7 / \mathrm{rN} 7$ & H5N7 & 0.287 & H7N7 & 0.479 & 0.108 & None & 3 & AADPGFNRGPCSDYDQRIDEYDY & $\mathrm{C}$ & MIRY \\
\hline 7 & IV 240 & 3049 & $\mathrm{rN} 7 / \mathrm{H} 5 \mathrm{~N} 7$ & H5N7 & 0.453 & H7N7 & 0.916 & 0.106 & None & 1 & AAGSQGWGLTDAARYAY & $\mathrm{D}$ & MIRY \\
\hline 8 & IV 265 & 3050 & $\mathrm{H} 10 \mathrm{~N} 8 / \mathrm{rN} 8$ & $\mathrm{H} 3 \mathrm{~N} 8$ & 0.812 & $\mathrm{ND}$ & & 0.232 & None & 3 & AAALYYSDYRGCSIYYGMDD & $\mathrm{A}$ & MIRY \\
\hline 8 & IV280 & 3050 & $\mathrm{rN} 8 / \mathrm{rN} 8$ & H3N8 & 0.475 & ND & & 1.042 & None & 2 & YYCAADRDERLWTYVTNMDY & B & MIRY \\
\hline 8 & IV268 & 3050 & $\mathrm{H} 10 \mathrm{~N} 8 / \mathrm{rN} 8$ & H3N8 & 0.707 & ND & & 0.172 & None & 1 & AAELDHGGAIMGVRRAQQYDY & $\mathrm{C}$ & MIRY \\
\hline 8 & IV274 & 3466 & $\mathrm{rN} 8 / \mathrm{H} 10 \mathrm{~N} 8$ & H3N8 & 0.474 & ND & & 0.183 & None & 2 & NAELVLGYGSAVDSYPMDY & $\mathrm{D}$ & MIRY \\
\hline 8 & IV275 & 3467 & $\mathrm{rN} 8 / \mathrm{H} 10 \mathrm{~N} 8$ & H3N8 & 0.134 & ND & & 0.527 & None & 2 & GLSHYLNWNVA & E & MIRY \\
\hline 8 & IV284 & 3466 & $\mathrm{rN} 8 / \mathrm{rN} 8$ & H3N8 & 0.119 & ND & & 0.769 & None & 1 & ASATASTYFSDGYVATAGHEYDS & $\mathrm{F}$ & MIRY \\
\hline$\ddot{9}$ & IV 525 & 3050 & IV $295 \mathrm{~F}$ H15N9/IV295F H15N9 & $\mathrm{H} 5 \mathrm{~N} 9^{\mathrm{g}}$ & 0.065 & $\mathrm{H} 5 \mathrm{~N} 9^{\mathrm{h}}$ & 0.073 & $\mathrm{ND}$ & None & 2 & NÄETHYRIDGDYDF & A & Episomal \\
\hline 9 & IV295 & 3050 & $\mathrm{rN} 9 / \mathrm{H} 5 \mathrm{~N} 9^{\mathrm{h}}$ & $\mathrm{H} 5 \mathrm{~N}^{\mathrm{g}}$ & ND & $\mathrm{H} 5 \mathrm{~N} 9^{\mathrm{h}}$ & 0.204 & 0.144 & None & 2 & RADGVVGGY & B & MIRY \\
\hline 9 & IV294 & 3050 & $\mathrm{rN} 9 / \mathrm{rN} 9$ & $\mathrm{H} 5 \mathrm{~N} 9^{\mathrm{g}}$ & ND & $\mathrm{H} 5 \mathrm{~N} 9^{\mathrm{h}}$ & 0.132 & 0.51 & None & 2 & NFQGGSSVLDRATFDY & $\mathrm{C}$ & MIRY \\
\hline 9 & IV300 & 3050 & $\mathrm{H} 5 \mathrm{N9}^{\mathrm{g}} \mathrm{cH} 5 \mathrm{~N} 7 / \mathrm{rN} 9$ & $\mathrm{H} 5 \mathrm{~N} 9^{\mathrm{g}}$ & ND & $\mathrm{H} 5 \mathrm{~N} 9^{\mathrm{h}}$ & 0.474 & 0.108 & None & 2 & NADIWAIATMRAGSYDY & $\mathrm{D}$ & MIRY \\
\hline 9 & IV530 & 3050 & IV295F H5N9/IV295F H15N9 & $\mathrm{H} 5 \mathrm{~N}^{\mathrm{g}}$ & 0.128 & $\mathrm{H} 5 \mathrm{~N} 9^{\mathrm{h}}$ & 0.446 & ND & None & 3 & AAGLGSLDRLLYDY & E & Episomal \\
\hline 9 & IV533 & 3050 & IV295F H5N9/IV295F H15N9 & $\mathrm{H} 5 \mathrm{~N} 9^{\mathrm{g}}$ & 0.089 & $\mathrm{H} 5 \mathrm{~N} 9^{\mathrm{h}}$ & 0.140 & ND & None & 2 & NALLEYRRWGEYEY & $\mathrm{F}$ & Episomal \\
\hline
\end{tabular}

a Superscript "ST" indicates the capture of rNA by streptavidin for immobilization to plates. Viruses that were directly coated are indicated by their subtype only. Capture with a coated VHH of Triton X-100 solubilized NA of whole virus is indicated by the name of the capturing VHH; ${ }^{\mathrm{b}}$ ELISA signal (absorbance at $450 \mathrm{~nm}$ ) of ten-fold diluted $E$. coli culture supernatant containing VHH incubated on plates coated with influenza viruses of different subtypes and detected with anti-myc mAb-peroxidase conjugate. Absorbance values are color coded as follows: $0.1-0.3$, light grey; $0.3-0.8$, medium grey; $>0.8$, dark grey. Homologous rNA indicates binding to rNA of the same subtype as to which the VHH is classified in the left column of Table. ND, not determined; ${ }^{\mathrm{c}}$ If present, the IMGT position of the Asn residue of the potential Nglycosylation site(s) is indicated; ${ }^{\mathrm{d}}$ As defined by [20]. C indicates conventional-like VHHs, which are often produced at reduced levels in microorganisms; ${ }^{\mathrm{e}} \mathrm{Clones}$ with identical complementarity determining region 3 (CDR3) length and more than $80 \%$ CDR3 amino acid sequence similarity are arranged in to the same CDR3 group, indicated by letters; ${ }^{\mathrm{f}}$ Episomal expression was done using plasmid pRL188. Some clones were produced at higher levels by replacing the episomal yeast replication origin of pRL188 by a MIRY-type replication origin. ${ }^{\mathrm{g}}$ Strain A/chicken/Italy/22A/1998. ${ }^{\mathrm{h}}$ Strain A/turkey/Wisconsin/1968. 
Table 5. Inhibition of rNA activity and binding in ELISA to influenza viruses of different subtypes of 64 yeast-produced VHHs.

\begin{tabular}{|c|c|c|c|c|c|c|c|c|c|c|c|c|c|c|c|c|c|c|c|c|c|c|}
\hline \multirow{2}{*}{$\begin{array}{l}\text { N } \\
\text { Sub- } \\
\text { type }\end{array}$} & \multirow[b]{2}{*}{$\begin{array}{l}\text { VHH } \\
\text { Clone } \\
\end{array}$} & \multirow{2}{*}{$\begin{array}{l}\text { rNA enzyme } \\
\text { inhibition }^{\mathrm{a}} \\
\left(\mathrm{IC}_{50} \text { in } \mathrm{ng} / \mathrm{mL}\right)\end{array}$} & \multicolumn{20}{|c|}{ ELISA signal on influenza virus ${ }^{b}$} \\
\hline & & & $\begin{array}{l}\text { H1 } \\
\text { N1 }\end{array}$ & $\begin{array}{l}\text { H7 } \\
\text { N1 }\end{array}$ & $\begin{array}{l}\text { H6 } \\
\text { N2 }\end{array}$ & $\begin{array}{l}\text { H9 } \\
\text { N2 }\end{array}$ & $\begin{array}{l}\mathrm{H} 2 \\
\mathrm{N3}\end{array}$ & $\begin{array}{l}\text { H8 } \\
\text { N4 }\end{array}$ & $\begin{array}{l}\text { H1 } \\
\text { N5 }\end{array}$ & $\begin{array}{l}\text { H6 } \\
\text { N5 }\end{array}$ & $\begin{array}{l}\text { H12 } \\
\text { N5 }\end{array}$ & $\begin{array}{l}\text { H11 } \\
\text { N6 }\end{array}$ & $\begin{array}{l}\text { H13 } \\
\text { N6 }\end{array}$ & $\begin{array}{l}\text { H14 } \\
\text { N6 }\end{array}$ & $\begin{array}{l}\text { H5 } \\
\text { N7 }\end{array}$ & $\begin{array}{l}\text { H7 } \\
\text { N7 }\end{array}$ & $\begin{array}{l}\text { H3 } \\
\text { N8 }\end{array}$ & $\begin{array}{l}\text { H4 } \\
\text { N8 }\end{array}$ & $\begin{array}{l}\text { H10 } \\
\text { N8 }\end{array}$ & $\begin{array}{l}\text { H5 } \\
\text { N9 }^{\mathbf{c}}\end{array}$ & $\begin{array}{l}\text { H5 } \\
\text { N9 }^{\text {d }}\end{array}$ & $\begin{array}{l}\text { H15 } \\
\text { N9 }\end{array}$ \\
\hline 1 & IV169F & ND & 0.06 & 0.60 & 0.05 & 0.05 & 0.05 & 0.05 & 0.05 & 0.05 & 0.06 & 0.05 & 0.05 & 0.06 & 0.06 & 0.06 & 0.05 & 0.06 & 0.05 & 0.05 & 0.05 & 0.05 \\
\hline 1 & IV403F & ND & 0.05 & 0.72 & 0.04 & 0.05 & 0.05 & 0.05 & 0.05 & 0.05 & 0.06 & 0.05 & 0.05 & 0.08 & 0.05 & 0.06 & 0.05 & 0.09 & 0.05 & 0.05 & 0.13 & 0.06 \\
\hline 1 & IV417F & ND & 0.05 & 0.07 & 0.04 & 0.05 & 0.05 & 0.05 & 0.06 & 0.05 & 0.06 & 0.05 & 0.12 & 0.11 & 0.06 & 0.07 & 0.06 & 0.12 & 0.06 & 0.06 & 0.10 & 0.06 \\
\hline 1 & IV171F & ND & 0.06 & 0.40 & 0.05 & 0.05 & 0.05 & 0.05 & 0.05 & 0.05 & 0.06 & 0.05 & 0.05 & 0.05 & 0.09 & 0.10 & 0.05 & 0.05 & 0.05 & 0.05 & 0.05 & 0.06 \\
\hline 1 & IV414F & ND & 0.04 & 0.05 & 0.04 & 0.05 & 0.18 & 0.05 & 0.05 & 0.05 & 0.05 & 0.05 & 0.05 & 0.10 & 0.05 & 0.06 & 0.05 & 0.09 & 0.05 & 0.05 & 0.17 & 0.06 \\
\hline 1 & IV426F & ND & 0.05 & 0.15 & 0.05 & 0.05 & 0.05 & 0.05 & 0.05 & 0.05 & 0.06 & 0.05 & 0.05 & 0.05 & 0.05 & 0.06 & 0.05 & 0.06 & 0.05 & 0.05 & 0.05 & 0.06 \\
\hline 1 & IV422F & ND & 0.06 & 1.02 & 0.05 & 0.05 & 0.05 & 0.05 & 0.05 & 0.05 & 0.06 & 0.05 & 0.05 & 0.07 & 0.06 & 0.07 & 0.05 & 0.08 & 0.05 & 0.05 & 0.06 & 0.06 \\
\hline 2 & IV63F & 15 & 0.06 & 0.06 & 0.13 & 0.12 & 0.05 & 0.05 & 0.05 & 0.05 & 0.05 & 0.06 & 0.06 & 0.07 & 0.06 & 0.06 & 0.05 & 0.05 & 0.05 & 0.05 & 0.05 & 0.06 \\
\hline 2 & IV82F & & 0.06 & 0.05 & 0.07 & 0.12 & 0.05 & 0.05 & 0.05 & 0.05 & 0.05 & 0.05 & 0.05 & 0.05 & 0.06 & 0.06 & 0.05 & 0.05 & 0.06 & 0.05 & 0.05 & 0.06 \\
\hline 2 & IV104F & 51 & 0.05 & 0.05 & 0.04 & 0.07 & 0.05 & 0.05 & 0.05 & 0.05 & 0.05 & 0.05 & 0.05 & 0.05 & 0.05 & 0.06 & 0.05 & 0.06 & 0.05 & 0.05 & 0.06 & 0.06 \\
\hline 2 & IV65F & 33 & 0.05 & 0.05 & 0.04 & 0.05 & 0.05 & 0.05 & 0.05 & 0.05 & 0.05 & 0.05 & 0.05 & 0.05 & 0.05 & 0.06 & 0.05 & 0.05 & 0.05 & 0.05 & 0.05 & 0.06 \\
\hline 2 & IV77F & $>1,000$ & 0.05 & 0.05 & 0.04 & 0.05 & 0.05 & 0.05 & 0.05 & 0.05 & 0.05 & 0.05 & 0.05 & 0.05 & 0.05 & 0.06 & 0.05 & 0.07 & 0.05 & 0.05 & 0.05 & 0.05 \\
\hline 2 & IV105F & 63 & 0.05 & 0.05 & 0.04 & 0.05 & 0.05 & 0.05 & 0.05 & 0.05 & 0.05 & 0.05 & 0.05 & 0.09 & 0.05 & 0.06 & 0.05 & 0.08 & 0.05 & 0.05 & 0.06 & 0.06 \\
\hline 2 & IV75F & 73 & 0.06 & 0.05 & 0.04 & 0.05 & 0.05 & 0.05 & 0.05 & 0.05 & 0.05 & 0.05 & 0.05 & 0.05 & 0.05 & 0.05 & 0.05 & 0.05 & 0.05 & 0.05 & 0.05 & 0.06 \\
\hline 2 & IV78F & 54 & 0.06 & 0.05 & 0.85 & 0.67 & 0.05 & 0.05 & 0.05 & 0.05 & 0.06 & 0.71 & 0.49 & 0.96 & 0.05 & 0.06 & 0.05 & 0.08 & 0.05 & 0.43 & 0.47 & 0.63 \\
\hline 2 & & & 0.05 & 0.05 & 0.10 & 0.07 & 0.05 & 0.05 & 0.05 & 0.05 & 0.05 & 0.05 & 0.05 & 0.05 & 0.05 & 0.06 & 0.05 & 0.05 & 0.05 & 0.05 & 0.05 & 0.06 \\
\hline 2 & IV97F & 71 & 0.04 & 0.05 & 0.05 & 0.09 & 0.05 & 0.05 & 0.05 & 0.05 & 0.05 & 0.05 & 0.05 & 0.04 & 0.05 & 0.06 & 0.05 & 0.05 & 0.05 & 0.05 & 0.05 & 0.06 \\
\hline 2 & IV107F & 63 & 0.06 & 0.05 & 0.05 & 0.05 & 0.05 & 0.05 & 0.05 & 0.05 & 0.06 & 0.05 & 0.05 & 0.11 & 0.06 & 0.07 & 0.05 & 0.09 & 0.06 & 0.06 & 0.07 & 0.06 \\
\hline 2 & $\mathrm{IV} 81 \mathrm{~F}^{\mathrm{e}}$ & 76 & 0.05 & 0.05 & 0.06 & 0.06 & 0.05 & 0.06 & 0.06 & 0.05 & 0.06 & 0.06 & 0.06 & 0.11 & 0.05 & 0.06 & 0.06 & 0.11 & 0.05 & 0.05 & 0.05 & 0.06 \\
\hline 2 & IV84F & 40 & 0.06 & 0.05 & 0.56 & 0.25 & 0.05 & 0.05 & 0.05 & 0.05 & 0.05 & 0.05 & 0.05 & 0.05 & 0.84 & 0.86 & 0.05 & 0.05 & 0.05 & 0.05 & 0.05 & 0.06 \\
\hline 3 & IV185F & 8 & 0.05 & 0.07 & 0.05 & 0.05 & 1.21 & 0.05 & 0.05 & 0.05 & 0.06 & 0.05 & 0.05 & 0.05 & 0.06 & 0.06 & 0.05 & 0.05 & 0.05 & 0.05 & 0.05 & 0.06 \\
\hline 3 & IV191F & 5 & 0.05 & 0.05 & 0.04 & 0.05 & 0.94 & 0.05 & 0.05 & 0.05 & 0.05 & 0.05 & 0.05 & 0.05 & 0.05 & 0.06 & 0.05 & 0.05 & 0.05 & 0.05 & 0.05 & 0.06 \\
\hline 3 & IV235F & $>1,000$ & 0.05 & 0.05 & 0.04 & 0.05 & 0.79 & 0.05 & 0.05 & 0.05 & 0.06 & 0.05 & 0.05 & 0.07 & 0.05 & 0.06 & 0.05 & 0.06 & 0.05 & 0.05 & 0.07 & 0.06 \\
\hline 3 & IV $456 \mathrm{~F}^{\mathrm{e}}$ & $>1,000$ & 0.06 & 0.05 & 0.05 & 0.05 & 1.39 & 0.05 & 0.06 & 0.05 & 0.07 & 0.06 & 0.05 & 0.08 & 0.06 & 0.06 & 0.05 & 0.07 & 0.06 & 0.06 & 0.06 & 0.06 \\
\hline 3 & IV187F & 2 & 0.05 & 0.05 & 0.05 & 0.05 & 0.24 & 0.05 & 0.05 & 0.05 & 0.06 & 0.05 & 0.05 & 0.05 & 0.06 & 0.06 & 0.05 & 0.05 & 0.05 & 0.05 & 0.05 & 0.06 \\
\hline 3 & IV $202 F^{\mathrm{e}}$ & 13 & 0.06 & 0.06 & 0.05 & 0.06 & 0.19 & 0.05 & 0.10 & 0.06 & 0.06 & 0.06 & 0.06 & 0.10 & 0.06 & 0.07 & 0.05 & 0.09 & 0.06 & 0.06 & 0.06 & 0.06 \\
\hline 3 & IV540F & ND & 0.04 & 0.05 & 0.04 & 0.05 & 0.05 & 0.05 & 0.05 & 0.05 & 0.06 & 0.05 & 0.06 & 0.05 & 0.05 & 0.06 & 0.05 & 0.06 & 0.07 & 0.05 & 0.05 & 0.07 \\
\hline
\end{tabular}


Table 5. Cont.

\begin{tabular}{|c|c|c|c|c|c|c|c|c|c|c|c|c|c|c|c|c|c|c|c|c|c|c|}
\hline \multirow{2}{*}{$\begin{array}{l}\text { N } \\
\text { Sub- } \\
\text { type }\end{array}$} & \multirow[b]{2}{*}{$\begin{array}{l}\text { VHH } \\
\text { Clone }\end{array}$} & \multirow{2}{*}{$\begin{array}{l}\text { rNA enzyme } \\
\text { inhibition }^{\mathrm{a}} \\
\left(\mathrm{IC}_{50} \text { in } \mathrm{ng} / \mathrm{mL}\right)\end{array}$} & \multicolumn{20}{|c|}{ ELISA signal on influenza virus ${ }^{b}$} \\
\hline & & & $\begin{array}{l}\text { H1 } \\
\text { N1 }\end{array}$ & $\begin{array}{l}\text { H7 } \\
\text { N1 }\end{array}$ & $\begin{array}{l}\text { H6 } \\
\text { N2 }\end{array}$ & $\begin{array}{l}\text { H9 } \\
\text { N2 }\end{array}$ & $\begin{array}{l}\mathrm{H} 2 \\
\mathrm{N3}\end{array}$ & $\begin{array}{l}\text { H8 } \\
\text { N4 }\end{array}$ & $\begin{array}{l}\text { H1 } \\
\text { N5 }\end{array}$ & $\begin{array}{l}\text { H6 } \\
\text { N5 }\end{array}$ & $\begin{array}{l}\text { H12 } \\
\text { N5 }\end{array}$ & $\begin{array}{l}\text { H11 } \\
\text { N6 }\end{array}$ & $\begin{array}{l}\text { H13 } \\
\text { N6 }\end{array}$ & $\begin{array}{l}\text { H14 } \\
\text { N6 }\end{array}$ & $\begin{array}{l}\mathbf{H 5} \\
\text { N7 } \\
\end{array}$ & $\begin{array}{l}\mathbf{H 7} \\
\text { N7 } \\
\end{array}$ & $\begin{array}{l}\text { H3 } \\
\text { N8 }\end{array}$ & $\begin{array}{l}\text { H4 } \\
\text { N8 }\end{array}$ & $\begin{array}{l}\text { H10 } \\
\text { N8 }\end{array}$ & $\begin{array}{l}\text { H5 } \\
\text { N9 }^{\text {c }} \\
\end{array}$ & $\begin{array}{l}\text { H5 } \\
\text { N9 }^{\text {d }}\end{array}$ & $\begin{array}{l}\text { H15 } \\
\text { N9 }\end{array}$ \\
\hline 4 & IV207F & ND & 0.06 & 0.05 & 0.05 & 0.05 & 0.05 & 0.23 & 0.05 & 0.05 & 0.06 & 0.05 & 0.05 & 0.09 & 0.05 & 0.07 & 0.05 & 0.08 & 0.05 & 0.05 & 0.07 & 0.06 \\
\hline 4 & IV215F & & 0.05 & 0.05 & 0.05 & 0.05 & 0.05 & 0.31 & & 0.05 & 0.06 & 0.05 & 0.05 & 0.05 & 0.06 & 0.06 & 0.05 & 0.05 & 0.05 & 0.05 & 0.05 & 0.06 \\
\hline 4 & IV213F & ND & 0.07 & 0.10 & 0.05 & 0.05 & 0.05 & 0.43 & 0.05 & 0.05 & 0.06 & 0.05 & 0.05 & 0.05 & 0.05 & 0.07 & 0.05 & 0.07 & 0.05 & 0.06 & 0.07 & 0.08 \\
\hline 4 & IV297F & ND & 0.05 & 0.10 & 0.04 & 0.05 & 0.05 & 0.64 & 0.05 & 0.05 & 0.06 & 0.05 & 0.05 & 0.05 & 0.06 & 0.06 & 0.05 & 0.06 & 0.05 & 0.06 & 0.07 & 0.07 \\
\hline 4 & $\mathrm{~J} 208 \mathrm{~F}$ & ND & 0.09 & 0.05 & 0.05 & 0.05 & 0.05 & 0.20 & 0.06 & 0.05 & 0.06 & 0.05 & 0.05 & 0.06 & 0.06 & 0.07 & 0.05 & 0.07 & 0.06 & 0.05 & 0.05 & 0.06 \\
\hline 5 & $\mathrm{~J} 224 \mathrm{~F}$ & & 0.04 & 0.05 & 0.04 & 0.05 & 0.05 & 0.05 & 0.09 & 0.08 & 0.12 & 0.05 & 0.05 & 0.05 & 0.05 & 0.06 & 0.05 & 0.05 & 0.05 & 0.05 & 0.05 & 0.06 \\
\hline 5 & $J 451 \mathrm{~F}$ & & 0.05 & 0.05 & 0.04 & 0.05 & 0.05 & 0.05 & 0.21 & 0.14 & 0.20 & 0.05 & 0.05 & 0.09 & 0.07 & 0.06 & 0.05 & 0.06 & 0.05 & 0.05 & 0.13 & 0.06 \\
\hline 5 & V442F & ND & 0.05 & 0.05 & 0.05 & 0.05 & 0.05 & 0.05 & 0.39 & 0.16 & 0.59 & 0.05 & 0.05 & 0.05 & 0.06 & 0.07 & 0.05 & 0.06 & 0.05 & 0.06 & 0.05 & 0.06 \\
\hline 5 & $\mathrm{~V} 447 \mathrm{~F}$ & ND & 0.04 & 0.05 & 0.04 & 0.05 & 0.05 & 0.05 & 0.48 & 0.22 & 0.79 & 0.05 & 0.05 & 0.05 & 0.05 & 0.06 & 0.05 & 0.05 & 0.05 & 0.05 & 0.05 & 0.06 \\
\hline 6 & V501F & ND & 0.04 & 0.05 & 0.04 & 0.05 & 0.05 & 0.05 & 0.05 & 0.05 & 0.06 & 0.05 & 0.67 & 0.10 & 0.05 & 0.06 & 0.05 & 0.05 & 0.05 & 0.05 & 0.05 & 0.06 \\
\hline 6 & $457 \mathrm{~F}$ & ND & 0.06 & 0.05 & 0.05 & 0.05 & 0.06 & 0.05 & 0.07 & 0.05 & 0.06 & 1.60 & 1.14 & 1.57 & 0.20 & 0.21 & 0.05 & 0.10 & 0.06 & 0.35 & 0.52 & 0.84 \\
\hline 6 & $512 \mathrm{~F}$ & & 0.05 & 0.05 & 0.04 & 0.05 & 0.05 & 0.05 & 0.05 & 0.06 & 0.06 & 1.58 & 1.13 & 1.51 & 0.05 & 0.06 & 0.05 & 0.06 & 0.05 & 0.05 & 0.05 & 0.06 \\
\hline 6 & $618 \mathrm{~F}$ & & 0.05 & 0.05 & 0.04 & 0.05 & 0.05 & 0.05 & 0.05 & 0.05 & 0.06 & 1.20 & 0.55 & 0.98 & 0.06 & 0.06 & 0.05 & 0.06 & 0.05 & 0.05 & 0.05 & 0.06 \\
\hline 6 & $461 \mathrm{~F}$ & D & 0.05 & 0.05 & 0.04 & 0.05 & 0.05 & 0.05 & 0.05 & 0.05 & 0.06 & 0.07 & 0.08 & 0.13 & 0.06 & 0.07 & 0.05 & 0.08 & 0.06 & 0.06 & 0.06 & 0.06 \\
\hline 6 & $462 \mathrm{~F}$ & & 0.05 & 0.07 & 0.04 & 0.05 & 0.05 & 0.05 & 0.05 & 0.05 & 0.06 & 0.59 & 0.05 & 0.27 & 0.06 & 0.06 & 0.05 & 0.05 & 0.06 & 0.05 & 0.05 & 0.06 \\
\hline 6 & $\sqrt{ } 467 \mathrm{~F}^{\mathrm{e}}$ & & 0.05 & 0.05 & 0.04 & 0.05 & 0.05 & 0.05 & 0.05 & 0.05 & 0.07 & 0.67 & 0.86 & 1.38 & 0.06 & 0.06 & 0.05 & 0.06 & 0.06 & 0.05 & 0.05 & 0.06 \\
\hline 6 & I513F & & 0.05 & 0.05 & 0.04 & 0.05 & 0.05 & 0.05 & 0.05 & 0.05 & 0.06 & 1.39 & 0.99 & 1.46 & 0.07 & 0.07 & 0.05 & 0.07 & 0.05 & 0.07 & 0.08 & 0.11 \\
\hline 6 & $514 \mathrm{~F}$ & JD & 0.05 & 0.05 & 0.04 & 0.05 & 0.05 & 0.05 & 0.06 & 0.05 & 0.06 & 1.08 & 0.74 & 1.20 & 0.06 & 0.06 & 0.05 & 0.10 & 0.05 & 0.05 & 0.07 & 0.06 \\
\hline 6 & J619F & & 0.05 & 0.06 & 0.04 & 0.05 & 0.05 & 0.05 & 0.05 & 0.05 & 0.06 & 0.92 & 0.64 & 1.08 & 0.05 & 0.06 & 0.05 & 0.09 & 0.05 & 0.05 & 0.10 & 0.06 \\
\hline 6 & $516 \mathrm{~F}$ & ND & 0.06 & 0.05 & 0.04 & 0.05 & 0.05 & 0.06 & 0.08 & 0.06 & 0.06 & 0.11 & 0.20 & 1.26 & 0.06 & 0.07 & 0.05 & 0.09 & 0.06 & 0.06 & 0.06 & 0.06 \\
\hline 7 & $246 \mathrm{~F}$ & 6 & 0.05 & 0.05 & 0.05 & 0.05 & 0.05 & 0.05 & 0.05 & 0.05 & 0.06 & 0.05 & 0.05 & 0.05 & 1.09 & 1.05 & 0.05 & 0.05 & 0.06 & 0.06 & 0.05 & 0.06 \\
\hline 7 & $252 \mathrm{~F}$ & 6 & 0.05 & 0.05 & 0.05 & 0.05 & 0.05 & 0.05 & 0.05 & 0.05 & 0.06 & 0.06 & 0.05 & 0.06 & 1.14 & 0.99 & 0.05 & 0.05 & 0.05 & 0.06 & 0.05 & 0.06 \\
\hline 7 & $242 \mathrm{~F}$ & 56 & 0.06 & 0.05 & 0.05 & 0.05 & 0.05 & 0.05 & 0.05 & 0.05 & 0.06 & 0.05 & 0.05 & 0.06 & 0.22 & 0.15 & 0.05 & 0.06 & 0.06 & 0.05 & 0.05 & 0.06 \\
\hline 7 & IV237F & 22 & 0.05 & 0.05 & 0.04 & 0.05 & 0.05 & 0.05 & 0.05 & 0.05 & 0.05 & 0.13 & 0.09 & 0.17 & 0.17 & 0.17 & 0.05 & 0.08 & 0.05 & 0.05 & 0.09 & 0.06 \\
\hline 7 & IV240F & 33 & 0.06 & 0.05 & 0.05 & 0.05 & 0.05 & 0.05 & 0.06 & 0.05 & 0.06 & 0.05 & 0.05 & 0.09 & 0.20 & 0.20 & 0.05 & 0.09 & 0.05 & 0.05 & 0.07 & 0.06 \\
\hline 8 & & & & 0.05 & 0.04 & 0.05 & 0.07 & 0.05 & & 0.05 & 0.06 & 0.05 & 0.05 & 0.05 & 0.06 & 0.06 & 0.13 & 0.33 & 0.10 & 0.05 & 0.05 & 0.06 \\
\hline 8 & IV280F & 201 & 0.05 & 0.05 & 0.04 & 0.05 & 0.05 & 0.05 & 0.06 & 0.05 & 0.07 & 0.05 & 0.08 & 0.10 & 0.05 & 0.07 & 0.19 & 1.44 & 0.14 & 0.06 & 0.15 & 0.06 \\
\hline 8 & IV268F & $>1000$ & 0.04 & 0.05 & 0.04 & 0.05 & 0.05 & 0.05 & 0.05 & 0.06 & 0.06 & 0.05 & 0.05 & 0.05 & 0.05 & 0.06 & 0.09 & 1.04 & 0.07 & 0.05 & 0.08 & 0.06 \\
\hline 8 & IV274F & 124 & 0.05 & 0.92 & 0.04 & 0.05 & 0.05 & 0.69 & 0.40 & 0.14 & 0.53 & 0.05 & 0.05 & 0.08 & 0.05 & 0.06 & 0.18 & 1.64 & 0.18 & 0.05 & 0.09 & 0.06 \\
\hline 8 & IV $275 \mathrm{~F}$ & $>1000$ & 0.04 & 0.05 & 0.05 & 0.05 & 0.05 & 0.05 & 0.05 & 0.05 & 0.06 & 0.05 & 0.06 & 0.12 & 0.06 & 0.06 & 0.08 & 0.70 & 0.06 & 0.06 & 0.12 & 0.06 \\
\hline 8 & IV284F & 8 & 0.06 & 0.05 & 0.05 & 0.05 & 0.05 & 0.05 & 0.05 & 0.05 & 0.06 & 0.05 & 0.05 & 0.07 & 0.06 & 0.07 & 0.06 & 0.13 & 0.06 & 0.05 & 0.05 & 0.06 \\
\hline 9 & IV 525F & $>1000$ & 0.06 & 0.05 & 0.04 & 0.05 & 0.05 & 0.05 & 0.06 & 0.05 & 0.06 & 0.06 & 0.06 & 0.05 & 0.06 & 0.07 & 0.06 & 0.06 & 0.06 & 0.06 & 0.05 & 1.24 \\
\hline
\end{tabular}


Table 5. Cont.

\begin{tabular}{|c|c|c|c|c|c|c|c|c|c|c|c|c|c|c|c|c|c|c|c|c|c|c|}
\hline \multirow{2}{*}{$\begin{array}{l}\text { N } \\
\text { Sub- } \\
\text { type }\end{array}$} & \multirow[b]{2}{*}{$\begin{array}{l}\text { VHH } \\
\text { Clone }\end{array}$} & \multirow{2}{*}{$\begin{array}{l}\text { rNA enzyme } \\
\text { inhibition }^{\text {a }} \\
\left(\mathrm{IC}_{\mathbf{5 0}} \text { in } \mathrm{ng} / \mathrm{mL}\right)\end{array}$} & \multicolumn{20}{|c|}{ ELISA signal on influenza virus ${ }^{b}$} \\
\hline & & & $\begin{array}{ll}\text { H1 } & \text { F } \\
\text { N1 } & \text { I } \\
\end{array}$ & $\begin{array}{l}\text { H7 } \\
\text { N1 } \\
\end{array}$ & $\begin{array}{l}\text { H6 } \\
\text { N2 } \\
\end{array}$ & $\begin{array}{ll}\text { H9 } & 1 \\
\text { N2 } & 1 \\
\end{array}$ & $\begin{array}{ll}\mathrm{H} 2 & \text { F } \\
\mathrm{N} 3 & \mathrm{I} \\
\end{array}$ & $\begin{array}{ll}\mathrm{H} 8 \\
\mathrm{~N} 4\end{array}$ & $\begin{array}{l}\text { H1 } \\
\text { N5 } \\
\end{array}$ & $\begin{array}{l}\text { H6 } \\
\text { N5 } \\
\end{array}$ & $\begin{array}{l}\text { H12 } \\
\text { N5 } \\
\end{array}$ & $\begin{array}{l}\text { H11 } \\
\text { N6 } \\
\end{array}$ & $\begin{array}{l}\text { H13 } \\
\text { N6 } \\
\end{array}$ & $\begin{array}{l}\text { H14 } \\
\text { N6 } \\
\end{array}$ & $\begin{array}{l}\text { H5 } \\
\text { N7 } \\
\end{array}$ & $\begin{array}{l}\mathbf{H 7} \\
\mathbf{N} 7 \\
\end{array}$ & $\begin{array}{l}\text { H3 } \\
\text { N8 }\end{array}$ & $\begin{array}{l}\text { H4 } \\
\text { N8 }\end{array}$ & $\begin{array}{l}\text { H10 } \\
\text { N8 }\end{array}$ & $\begin{array}{l}\text { H5 } \\
\text { N9 }\end{array}$ & $\begin{array}{l}\text { H5 } \\
\text { N9 }^{\text {d }}\end{array}$ & $\begin{array}{l}\text { H15 } \\
\text { N9 }\end{array}$ \\
\hline 9 & IV295F & $>1000$ & 0.05 & 0.05 & 0.04 & 0.05 & 0.05 & 0.05 & 0.05 & 0.05 & 0.06 & 0.05 & 0.05 & 0.05 & 0.06 & 0.06 & 0.05 & 0.05 & 0.06 & 0.35 & 0.08 & 1.23 \\
\hline 9 & IV294F & $>1000$ & 0.05 & 0.05 & 0.06 & 0.05 & 0.05 & 0.11 & 0.05 & 0.05 & 0.06 & 0.06 & 0.07 & 0.11 & 0.06 & 0.07 & 0.05 & 0.08 & 0.06 & 0.07 & 0.09 & 0.10 \\
\hline 9 & IV300F & 100 & 0.10 & 0.05 & 0.16 & 0.08 & $8 \quad 0.16$ & 0.05 & 0.05 & 0.05 & 0.06 & 0.07 & 0.06 & 0.08 & 0.05 & 0.06 & 0.05 & 0.06 & 0.05 & 0.11 & 0.31 & 0.33 \\
\hline \multirow[t]{2}{*}{9} & IV533F & 7 & 0.05 & 0.04 & 0.05 & 0.05 & 0.05 & 0.05 & 0.05 & 0.05 & 0.06 & 0.05 & 0.05 & 0.05 & 0.06 & 0.06 & 0.05 & 0.05 & 0.05 & 0.24 & 0.47 & 0.70 \\
\hline & None & $>1000$ & 0.05 & 0.05 & 0.04 & 0.05 & 0.05 & 0.05 & 0.05 & 0.06 & 0.06 & 0.05 & 0.05 & 0.05 & 0.05 & 0.06 & 0.05 & 0.05 & 0.05 & 0.06 & 0.06 & 0.08 \\
\hline
\end{tabular}

${ }^{\mathrm{a}}$ The VHH concentration causing $50 \%$ inhibition of the enzymatic activity $\left(\mathrm{IC}_{50}\right.$ ) of the homologous rNA, as measured by a fetuin-PNA-PO ELISA. $>1,000$, less than $50 \%$ inhibition at highest VHH concentration analyzed. ND, not determined because rNA was inactive or unavailable. ${ }^{\mathrm{b}}$ ELISA signal (A $450 \mathrm{~nm}$ ) of $1 \mu \mathrm{g} / \mathrm{mL}$ yeastproduced VHH incubated on plates coated with influenza viruses of different subtypes and detected with anti-his6 mAb-peroxidase conjugate. $\mathrm{A}_{450 \mathrm{~nm}}$ values are color coded: 0.1-0.3, light grey; 0.3-0.6, medium grey; >0.6, dark grey. ${ }^{\mathrm{c}}$ Strain A/chicken/Italy/22A/1998. ${ }^{\mathrm{d}}$ Strain A/turkey/Wisconsin/1968. ${ }^{\mathrm{e}}$ VHH was deglycosylated by endoglycosidase $\mathrm{H}$ treatment.

Figure 1. Analysis of N-glycosylation of yeast-produced VHHs. Five VHHs containing potential N-glycosylation sites were deglycosylated by endoglycosidase $\mathrm{H}$ treatment $(+)$ or mock-incubated $(-)$ prior to analysis by reducing SDS-PAGE. The position of relevant molecular mass markers (Benchmark ${ }^{\mathrm{TM}}$ protein ladder, Invitrogen) is indicated on the right.

VHH: IV81F IV84F IV202F IV456F IV467F

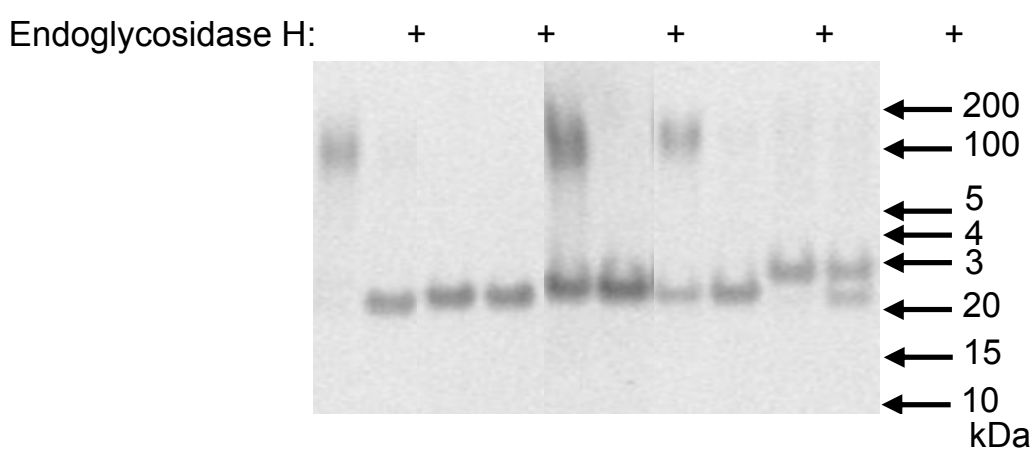


Table 6. Binding in ELISA of yeast-produced and biotinylated VHHs to influenza viruses of different subtypes.

\begin{tabular}{|c|c|c|c|c|c|c|c|c|c|c|c|c|c|c|c|c|c|c|c|c|c|c|}
\hline \multirow{3}{*}{$\begin{array}{l}\text { N- } \\
\text { Subtype }\end{array}$} & \multirow[b]{3}{*}{ VHH Clone } & \multicolumn{21}{|c|}{ ELISA signal on influenza viruses ${ }^{a}$} \\
\hline & & H1 & H7 & H6 & H9 & H2 & H8 & H1 & H6 & H12 & H11 & H13 & H14 & H5 & H7 & $\mathbf{H 3}$ & H4 & H10 & H5 & H5 & H15 & \\
\hline & & N1 & N1 & N2 & N2 & N3 & N4 & N5 & N5 & N5 & N6 & N6 & N6 & N7 & N7 & N8 & N8 & N8 & $\mathbf{N} 9^{b}$ & $\mathbf{N 9 ^ { c }}$ & N9 & None \\
\hline 1 & IV169F & 0.16 & 1.53 & 0.13 & 0.24 & 0.07 & 0.11 & 0.08 & 0.25 & 0.23 & 0.12 & 0.20 & 0.14 & 0.28 & 0.19 & 0.11 & 0.11 & 0.15 & 0.12 & 0.21 & 0.22 & 0.06 \\
\hline 1 & IV403F & 0.08 & 1.43 & 0.07 & 0.12 & 0.46 & 0.06 & 0.07 & 0.12 & 0.13 & 0.11 & 0.13 & 0.09 & 0.08 & 0.10 & 0.11 & 0.08 & 0.07 & 0.13 & 0.12 & 0.07 & 0.05 \\
\hline 1 & IV417F & 0.07 & 1.36 & 0.07 & 0.10 & 0.07 & 0.06 & 0.07 & 0.10 & 0.12 & 0.10 & 0.11 & 0.07 & 0.06 & 0.09 & 0.06 & 0.14 & 0.06 & 0.07 & 0.12 & 0.07 & 0.05 \\
\hline 1 & IV171F & 0.08 & 1.78 & 0.07 & 0.14 & 0.07 & 0.07 & 0.08 & 0.12 & 0.13 & 0.11 & 0.14 & 0.09 & 0.46 & 0.33 & 0.07 & 0.07 & 0.07 & 0.07 & 0.08 & 0.07 & 0.05 \\
\hline 1 & IV422F & 0.74 & 1.70 & 0.08 & 0.13 & 0.08 & 0.84 & 0.08 & 0.13 & 0.12 & 0.12 & 0.13 & 0.09 & 0.08 & 0.11 & 0.10 & 0.15 & 0.08 & 0.08 & 0.09 & 0.07 & 0.05 \\
\hline 2 & IV82F & 0.07 & 0.07 & 0.54 & 1.32 & 0.06 & 0.06 & 0.09 & 0.10 & 0.12 & 0.09 & 0.12 & 0.07 & 0.06 & 0.07 & 0.07 & 0.06 & 0.15 & 0.07 & 0.07 & 0.06 & 0.05 \\
\hline 2 & IV105F & 0.08 & 0.07 & 0.15 & 0.84 & 0.07 & 0.07 & 0.07 & 0.13 & 0.14 & 0.09 & 0.13 & 0.08 & 0.06 & 0.07 & 0.07 & 0.08 & 0.08 & 0.06 & 0.08 & 0.07 & 0.06 \\
\hline 2 & IV75F & 0.10 & 0.09 & 0.09 & 1.03 & 0.08 & 0.07 & 0.10 & 0.15 & 0.14 & 0.11 & 0.15 & 0.11 & 0.08 & 0.08 & 0.08 & 0.07 & 0.09 & 0.07 & 0.10 & 0.08 & 0.06 \\
\hline 2 & IV97F & 0.12 & 0.08 & 0.42 & 1.16 & 0.07 & 0.08 & 0.08 & 0.13 & 0.12 & 0.10 & 0.13 & 0.09 & 0.08 & 0.08 & 0.07 & 0.07 & 0.07 & 0.06 & 0.10 & 0.07 & 0.07 \\
\hline 2 & IV $81 F^{d}$ & 0.08 & 0.08 & 1.29 & 1.26 & 0.07 & 0.06 & 0.08 & 0.11 & 0.13 & 0.11 & 0.15 & 0.10 & 0.07 & 0.09 & 0.12 & 0.09 & 0.07 & 0.07 & 0.08 & 0.07 & 0.05 \\
\hline 2 & IV84F & 0.07 & 0.07 & 1.42 & 1.24 & 0.07 & 0.06 & 0.07 & 0.10 & 0.11 & 0.10 & 0.12 & 0.08 & 1.50 & 1.25 & 0.09 & 0.07 & 0.11 & 0.07 & 0.07 & 0.06 & 0.05 \\
\hline 3 & IV191F & 0.07 & 0.08 & 0.08 & 0.13 & 1.58 & 0.06 & 0.09 & 0.11 & 0.11 & 0.10 & 0.12 & 1.21 & 0.65 & 0.14 & 0.07 & 0.07 & 0.13 & 0.06 & 0.09 & 0.07 & 0.05 \\
\hline 3 & IV $235 \mathrm{~F}$ & 0.08 & 0.08 & 0.07 & 0.12 & 1.83 & 0.06 & 0.08 & 0.11 & 0.12 & 0.11 & 0.12 & 0.08 & 0.06 & 0.08 & 0.07 & 0.09 & 0.06 & 0.07 & 0.09 & 0.07 & 0.05 \\
\hline 3 & IV456F & 0.14 & 0.11 & 0.12 & 0.14 & 1.82 & 0.07 & 0.12 & 0.16 & 0.15 & 0.13 & 0.21 & 0.18 & 0.10 & 0.11 & 0.18 & 0.10 & 0.13 & 0.10 & 0.10 & 0.09 & 0.06 \\
\hline 3 & IV187F & 0.09 & 0.12 & 0.33 & 0.13 & 1.42 & 0.06 & 0.09 & 0.12 & 0.14 & 0.11 & 0.14 & 0.10 & 0.09 & 0.08 & 0.09 & 0.06 & 0.07 & 0.11 & 0.14 & 0.07 & 0.05 \\
\hline 3 & IV $202 \mathrm{~F}^{\mathrm{d}}$ & 0.11 & 1.42 & 0.09 & 0.14 & 1.57 & 0.06 & 0.11 & 0.15 & 0.15 & 0.15 & 0.19 & 0.14 & 0.09 & 0.10 & 0.16 & 0.54 & 0.09 & 0.08 & 0.10 & 0.08 & 0.06 \\
\hline 3 & IV540F & 0.07 & 0.09 & 0.07 & 0.11 & 0.08 & 0.06 & 0.08 & 0.12 & 0.13 & 0.11 & 0.15 & 0.10 & 0.07 & 0.09 & 0.12 & 0.11 & 0.08 & 0.07 & 0.09 & 0.07 & 0.05 \\
\hline 4 & IV215F & 0.08 & 0.07 & 0.06 & 0.12 & 0.06 & 1.47 & 0.07 & 0.12 & 0.12 & 0.10 & 0.13 & 0.07 & 0.07 & 0.07 & 0.07 & 0.11 & 0.08 & 0.06 & 0.08 & 0.07 & 0.06 \\
\hline 4 & IV $213 \mathrm{~F}$ & 1.21 & 1.17 & 0.56 & 0.17 & 0.29 & 1.43 & 0.08 & 0.10 & 0.12 & 0.09 & 0.12 & 0.07 & 0.10 & 0.09 & 0.08 & 1.12 & 0.07 & 0.47 & 0.90 & 0.97 & 0.06 \\
\hline 4 & IV208F & 0.96 & 0.08 & 0.08 & 0.12 & 0.10 & 1.21 & 0.67 & 0.10 & 0.12 & 0.10 & 0.13 & 0.09 & 0.10 & 0.07 & 0.06 & 0.06 & 0.06 & 0.07 & 0.09 & 0.07 & 0.05 \\
\hline 5 & IV224F & 0.07 & 0.08 & 0.07 & 0.14 & 0.07 & 0.06 & 1.31 & 1.18 & 1.59 & 0.10 & 0.13 & 0.08 & 0.07 & 0.07 & 0.07 & 0.06 & 0.06 & 0.07 & 0.09 & 0.06 & 0.05 \\
\hline 5 & IV451F & 0.07 & 0.07 & 0.07 & 0.12 & 0.08 & 0.06 & 1.29 & 1.35 & 1.55 & 0.10 & 0.12 & 0.07 & 0.07 & 0.07 & 0.06 & 0.06 & 0.06 & 0.07 & 0.08 & 0.07 & 0.05 \\
\hline 6 & IV501F & 0.07 & 0.12 & 0.07 & 0.11 & 0.06 & 0.06 & 0.07 & 0.10 & 0.12 & 0.10 & 1.44 & 1.50 & 0.06 & 0.14 & 0.07 & 0.09 & 0.06 & 0.08 & 0.08 & 0.07 & 0.05 \\
\hline 6 & IV512F & 0.80 & 0.13 & 0.60 & 0.35 & 0.84 & 0.06 & 0.40 & 0.19 & 0.30 & 1.49 & 1.42 & 1.41 & 0.36 & 0.35 & 0.08 & 0.65 & 0.07 & 0.08 & 0.08 & 0.07 & 0.05 \\
\hline 6 & IV618F & 0.61 & 0.12 & 0.65 & 0.34 & 0.74 & 0.06 & 0.34 & 0.13 & 0.26 & 1.38 & 1.40 & 1.37 & 0.68 & 0.58 & 0.10 & 0.39 & 0.08 & 0.08 & 0.09 & 0.08 & 0.06 \\
\hline 6 & IV461F & 0.07 & 0.07 & 0.08 & 0.11 & 0.07 & 0.06 & 0.09 & 0.10 & 0.13 & 1.11 & 1.19 & 1.34 & 0.06 & 0.07 & 0.12 & 0.07 & 0.09 & 0.07 & 0.08 & 0.07 & 0.06 \\
\hline 6 & IV $467 \mathrm{~F}^{\mathrm{d}}$ & 0.08 & 0.12 & 0.08 & 0.14 & 0.07 & 0.07 & 0.13 & 0.13 & 0.15 & 1.38 & 1.53 & 1.58 & 0.24 & 0.18 & 0.09 & 0.08 & 0.10 & 0.06 & 0.12 & 0.09 & 0.06 \\
\hline 6 & IV513F & 0.08 & 0.07 & 0.07 & 0.12 & 0.06 & 0.06 & 0.08 & 0.10 & 0.12 & 1.41 & 1.32 & 1.37 & 1.24 & 1.11 & 0.07 & 0.13 & 0.06 & 0.77 & 1.14 & 1.25 & 0.05 \\
\hline 6 & IV514F & 0.08 & 0.08 & 0.07 & 0.12 & 0.06 & 0.06 & 0.07 & 0.10 & 0.13 & 1.50 & 1.42 & 1.55 & 0.49 & 0.43 & 0.08 & 0.07 & 0.07 & 0.08 & 0.08 & 0.07 & 0.06 \\
\hline 6 & IV619F & 0.07 & 0.08 & 0.07 & 0.12 & 0.07 & 0.06 & 0.07 & 0.09 & 0.15 & 1.42 & 1.38 & 1.45 & 0.08 & 0.12 & 0.12 & 0.15 & 0.08 & 0.07 & 0.07 & 0.06 & 0.05 \\
\hline 6 & IV516F & 0.09 & 0.08 & 0.07 & 0.12 & 0.07 & 0.10 & 0.08 & 0.11 & 0.13 & 1.25 & 1.27 & 1.44 & 0.07 & 0.08 & 0.07 & 0.07 & 0.07 & 0.08 & 0.09 & 0.08 & 0.05 \\
\hline 7 & IV242F & 0.08 & 0.08 & 0.07 & 0.26 & 0.07 & 0.07 & 0.08 & 0.11 & 0.12 & 0.11 & 0.13 & 0.09 & 1.68 & 1.57 & 0.07 & 0.08 & 0.07 & 0.08 & 0.09 & 0.07 & 0.05 \\
\hline 7 & IV237F & 0.08 & 0.07 & 0.07 & 0.12 & 0.08 & 0.06 & 0.09 & 0.12 & 0.13 & 1.55 & 1.56 & 1.60 & 1.65 & 1.60 & 0.09 & 0.13 & 0.08 & 0.07 & 0.09 & 0.07 & 0.05 \\
\hline 7 & IV $240 \mathrm{~F}$ & 0.07 & 0.08 & 0.07 & 0.12 & 0.07 & 0.06 & 0.07 & 0.10 & 0.12 & 0.12 & 0.14 & 0.11 & 1.53 & 1.42 & 0.08 & 0.11 & 0.06 & 0.09 & 0.09 & 0.08 & 0.05 \\
\hline 8 & IV268F & 0.94 & 1.14 & 0.27 & 0.14 & 0.15 & 1.45 & 0.07 & 0.09 & 0.11 & 0.09 & 0.12 & 0.06 & 0.08 & 0.08 & 0.82 & 1.76 & 0.68 & 0.38 & 0.79 & 0.90 & 0.05 \\
\hline 8 & IV $275 \mathrm{~F}$ & 0.09 & 0.09 & 0.07 & 0.14 & 0.07 & 0.07 & 0.09 & 0.13 & 0.13 & 0.15 & 0.17 & 0.15 & 0.08 & 0.08 & 0.64 & 1.61 & 0.55 & 0.14 & 0.11 & 0.31 & 0.06 \\
\hline 8 & IV $284 \mathrm{~F}$ & 0.07 & 0.07 & 0.07 & 0.10 & 0.07 & 0.06 & 0.09 & 0.12 & 0.13 & 0.09 & 0.13 & 0.09 & 0.06 & 0.07 & 0.54 & 1.50 & 0.49 & 0.07 & 0.08 & 0.07 & 0.06 \\
\hline 9 & IV $525 \mathrm{~F}$ & 0.07 & 0.07 & 0.07 & 0.12 & 0.07 & 0.06 & 0.07 & 0.10 & 0.13 & 0.10 & 0.12 & 0.10 & 0.07 & 0.07 & 0.16 & 0.67 & 0.16 & 0.07 & 0.08 & 1.55 & 0.06 \\
\hline 9 & IV295F & 0.08 & 0.07 & 0.07 & 0.13 & 0.07 & 0.06 & 0.08 & 0.11 & 0.13 & 0.10 & 0.13 & 0.10 & 0.06 & 0.08 & 0.09 & 0.06 & 0.06 & 1.23 & 1.40 & 1.61 & 0.05 \\
\hline 9 & IV530F & 0.08 & 0.10 & 0.09 & 0.12 & 0.08 & 0.06 & 0.10 & 0.12 & 0.15 & 0.12 & 0.23 & 0.15 & 0.07 & 0.08 & 0.21 & 0.08 & 0.14 & 1.19 & 1.41 & 1.55 & 0.06 \\
\hline \multirow[t]{2}{*}{9} & IV533F & 0.07 & 0.09 & 0.08 & 0.13 & 0.13 & 0.06 & 0.07 & 0.10 & 0.14 & 0.15 & 0.16 & 0.09 & 0.07 & 0.08 & 0.13 & 0.09 & 0.09 & 0.59 & 0.88 & 1.22 & 0.06 \\
\hline & None & 0.06 & 0.07 & 0.06 & 0.10 & 0.06 & 0.06 & 0.06 & 0.10 & 0.11 & 0.08 & 0.11 & 0.06 & 0.05 & 0.06 & 0.06 & 0.05 & 0.06 & 0.06 & 0.06 & 0.06 & 0.05 \\
\hline
\end{tabular}

ELISA signal $\left(\mathrm{A}_{450} \mathrm{~mm}\right)$ of $1 \mu \mathrm{g} / \mathrm{mL}$ yeast-produced biotinylated $\mathrm{VHH}$ incubated on plates coated with influenza viruses of different subtype and detected with streptavidin-peroxidase conjugate. Absorbance values are color coded: $0.2-0.5$, light grey; $0.5-1$, medium grey; above 1 , dark grey. ${ }^{\mathrm{b}}$ Strain A/chicken/Italy/22A/1998. ${ }^{\mathrm{c}} \mathrm{Strain} \mathrm{A} /$ turkey/Wisconsin/1968. ${ }^{\mathrm{d}}$ These VHHs were deglycosylated by endoglycosidase $\mathrm{H}$ treatment. 
Most VHHs bound specifically to only one N-subtype virus. Some clones, such as IV417F (N1) and IV501F (N6), even bound specifically to particular virus strains of this subtype. Such strain-specific binding is not unexpected, since HA and NA proteins of influenza virus rapidly mutate, and under selective pressure from the host immune response, novel antigenic variants are constantly selected, a process known as antigenic drift [9]. Other VHHs, however, cross-react to influenza viruses of a different $\mathrm{N}$ subtype. The VHHs showing the strongest cross-reaction are summarized in Table 7.

Table 7. Summary of VHHs that bind to at least two different NA subtypes in ELISA.

\begin{tabular}{|c|c|c|c|c|c|c|c|c|c|c|}
\hline \multirow{2}{*}{$\begin{array}{l}\text { N } \\
\text { Sub- } \\
\text { type }\end{array}$} & \multirow{2}{*}{$\begin{array}{l}\text { VHH } \\
\text { Clone }\end{array}$} & \multicolumn{9}{|c|}{ VHH binding in ELISA to several NAs } \\
\hline & & N1 & N2 & $\mathbf{N 3}$ & $\mathrm{N} 4$ & N5 & N6 & N7 & N8 & N9 \\
\hline 1 & IV422F & $+{ }^{a}$ & - & - & + & - & - & - & - & - \\
\hline 4 & $208 \mathrm{~F}$ & + & - & - & + & + & - & - & - & - \\
\hline 4 & $213 \mathrm{~F}$ & + & + & - & + & - & - & - & + & + \\
\hline 8 & $274 \mathrm{~F}$ & + & - & - & + & + & - & - & + & - \\
\hline 8 & $268 \mathrm{~F}$ & + & - & - & + & - & - & - & + & + \\
\hline 9 & I525F & - & - & - & - & - & - & - & + & + \\
\hline 2 & $78 \mathrm{~F}$ & - & + & - & - & - & + & - & - & + \\
\hline 2 & $84 \mathrm{~F}$ & - & + & - & - & - & - & + & - & - \\
\hline 3 & $202 \mathrm{~F}$ & + & - & + & - & - & - & - & + & - \\
\hline 3 & IV191F & - & - & + & - & - & + & + & - & - \\
\hline 7 & $\mathrm{~V} 237 \mathrm{~F}$ & - & - & - & - & - & + & + & - & - \\
\hline 6 & V513F & - & - & - & - & - & + & + & - & + \\
\hline 6 & IV512F & + & + & + & - & - & + & - & + & - \\
\hline 6 & IV618F & + & + & + & - & - & + & + & - & - \\
\hline
\end{tabular}

${ }^{\mathrm{a}}+$, positive binding to at least one virus of the $\mathrm{N}$-subtype indicated with $\mathrm{A}_{450 \mathrm{~nm}}>0.5$ using biotinylated VHH (Table 6) or $\mathrm{A}_{450 \mathrm{~nm}}>0.3$ using non-biotinylated VHH (Table 5); -, no positive binding.

Most of the observed cross-reaction corresponds to the phylogenetic relationship between the different $\mathrm{N}$ subtypes. A phylogenetic tree (Figure 2) of the NA proteins of the strains used for rNA production (Table 3) closely resembles a previously published tree of NA proteins derived from other strains [8], showing the generality of this tree for different strains. N1 is most related to N4 and somewhat more distantly to N5 and N8 (Figure 2). Consistent with this, five clones bind both N1 and N4, two of which also bind N5 and three of which also bind N8 (Table 7). The binding of four clones to both N6 and N7 (Table 7) is also consistent with the close phylogenetic relationship between N6 and N7. However, some cross-reaction is not explained by a close phylogenetic relationship, such as the binding of IV525F to the distantly related N8 and N9. Furthermore, IV512F and IV618F, which belong to the same CDR3 group (Table 4), bind to NAs of as much as five subtypes (Table 7), according to the criterion used $\left(\mathrm{A}_{450 \mathrm{~nm}}>0.5\right.$ in Table 6). Using a less stringent criterion $\left(\mathrm{A}_{450 \mathrm{~nm}}=0.2-0.5\right.$ in Table 6$)$, these VHHs also bind to other viruses, including N5 subtype viruses. Such broad cross-reaction with sometimes even lower absorbance values is also observed with N3binder, IV456F, and N4-binder, IV213F (Table 6). 
Figure 2. Phylogenetic tree of the nine influenza A virus $N$ subtypes used in this study. The protein sequences of the complete NA of the nine strains used for recombinant NA production (Table 3) were aligned and used for phylogenetic analysis. The statistical support as measured by 100 cycles of bootstrap analysis is indicated at each node.

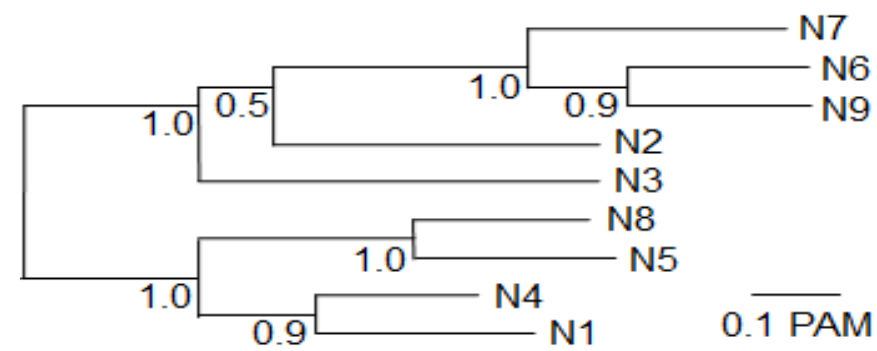

We further analyzed the cross-reaction of IV512F with many different subtypes in a sandwich ELISA setup by coating plates with IV512F and subsequent detection of bound NA of various Triton $\mathrm{X}-100$ solubilized subtypes. This confirmed the binding to the various subtypes observed in the direct ELISA, including N5, although binding to N1 and N6 was inefficient (Figure 3). Furthermore, in sandwich ELISA, IV512F bound to one of the two N9 viruses used. Thus, IV512F binds to influenza viruses off all subtypes, except N4, although not to all viruses of each subtype.

Figure 3. Cross-reaction of IV512F to NAs of different subtypes in sandwich ELISA. Plates were coated with or without (Mock) IV512F and incubated with Triton X-100 solubilized viruses of different subtypes. $\mathrm{C}$ indicates control incubation without influenza virus. Bound NA was subsequently detected using different biotinylated VHHs recognizing the various NAs. The H5N9 strain used was A/chicken/Italy/22A/1998.

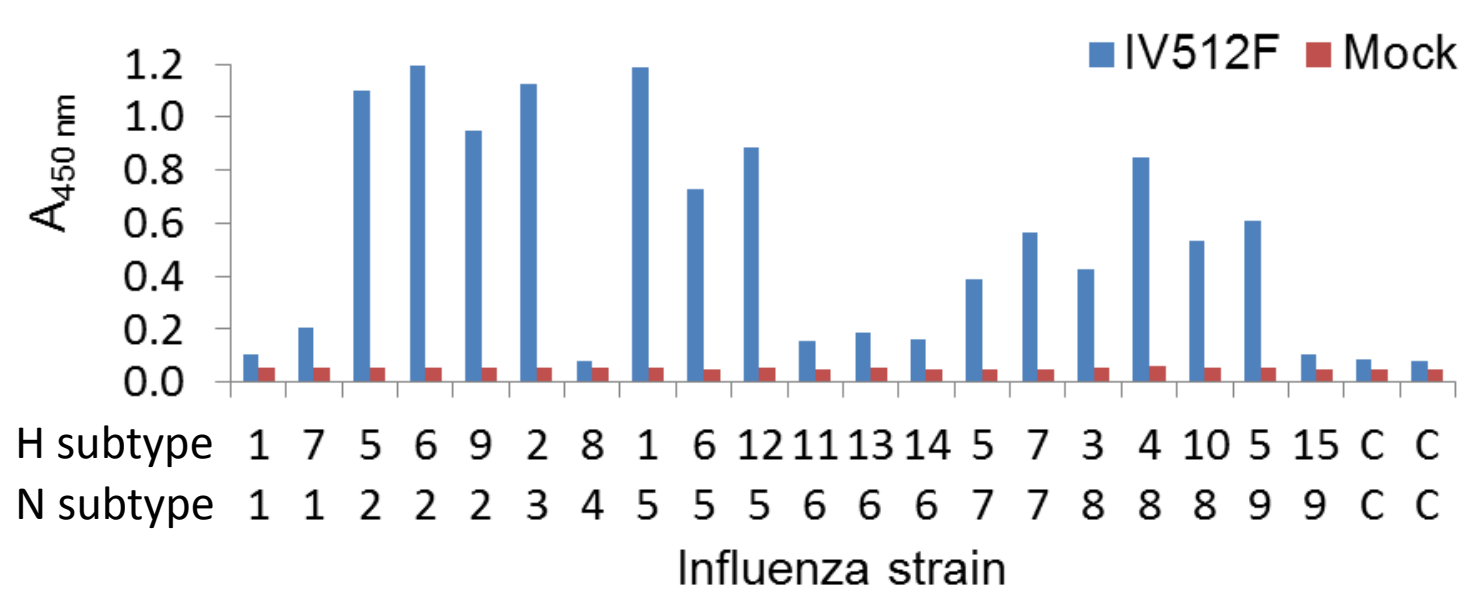

Two universally conserved epitopes in NA of all nine subtypes have been identified earlier by bioinformatic analysis and subsequent antibody generation using peptide immunization [12]. One of these epitopes is close to the NA enzymatic site, whereas the other is located near the NA N-terminus, which forms the cytoplasmic tail. Possibly IV512F and the related VHH IV618F bind to one of these 
epitopes. The binding to these epitopes was improved by detergent treatment, which was critically dependent on detergent concentration [12]. Thus, different absorbance values obtained when IV512F was analyzed by direct (Table 6) or sandwich ELISA (Figure 3) could be due to the use of detergent only in the latter assay.

The ability of IV512F to recognize a conserved epitope on NA could be due to the small size of a VHH. It has previously been suggested that some VHHs can recognize antigenic sites that are not recognized by the larger conventional antibody fragments, because these sites are located in cavities or clefts that can only be accessed by small antibody fragments. This is exemplified by VHHs binding to the enzyme active site of carbonic anhydrase or alpha-amylase [28] or to cryptic epitopes on the trypanosome surface [29]. Interestingly, this trypanosome antigenic site is conserved and lies underneath a layer of surface glycoproteins that is immunodominant and shows high antigenic variation to evade the host immune response.

We also measured the ability of VHHs to inhibit rNA enzymatic activity (Table 5). Evidently, this could only be done for rNA preparations that showed enzymatic activity (rN2, rN3, rN7, rN8 and rN9). Most VHHs neutralized rNA, consistent with earlier observations with conventional antibodies [9]. Several VHHs do not reach 50\% inhibition at the highest VHH concentration analyzed. Clone IV77F inhibits at most $40 \%$ of the $\mathrm{rN} 2$, but does this at low $\mathrm{VHH}$ concentrations $\left(\mathrm{IC}_{20}=3 \mathrm{ng} / \mathrm{mL}\right)$. This could indicate that IV77F recognizes an epitope that is present in only $40 \%$ of the $\mathrm{rN} 2$ molecules. Clones, IV235F and IV456F, which belong to the same CDR3 group, also do not inhibit rN3, although they bind to H2N3 virus (Table 5), which was also used for $\mathrm{rN} 3$ production. These clones possibly bind to an epitope that is not involved in enzyme activity. The absence of rNA inhibition by clones, IV268F (N8), IV275F (N8), IV294F (N9), IV295F (N9) and IV525F (N9), could be due to their strain-specific binding (Table 5), since the rNA was derived from a different strain than used in ELISA. The cross-reaction of VHHs to viruses of different $\mathrm{N}$ subtype never correlates with their H subtype, making it unlikely that the cross-reaction is due to HA binding. Further proof that the selected VHHs bind to NA is based on their binding to rNA (Table 4) or inhibition of rNA enzyme activity (Table 5), which is, however, only available for enzymatically active rNA. The NA binding specificity of IV512F is further proven by its binding to different NAs in sandwich ELISA with other, biotinylated VHHs that unequivocally bind NA, because they bind rNA (Table 4).

\section{Experimental}

\subsection{Animals}

Four one-year-old llamas (Lama glama) were used for this study. They were provided with food and water ad libitum. Animal experiments were performed under the supervision of the Animal Experimental Committee according to the Dutch Act on Experimental Animal Use.

\subsection{Expression of Soluble Recombinant NA}

Human codon-optimized sequences encoding the soluble NA head domain of nine influenza viruses representing the nine NA subtypes (Table 3) were synthesized (GenScript Corporation, Piscataway, NJ, USA) and cloned into a derivative of expression plasmid pS1-Ig for expression in HEK293T cells, 
as described previously [11]. The NA gene was preceded by sequences successively coding for an N-terminal human CD5 signal peptide (MPMGSLQPLATLYLLGMLVASVLA), a double Strep tag (WSHPQFEKGGGSGGGSGGGSWSHPQFEK; One-STrEP; IBA GmbH, Göttingen, Germany), an artificial yeast GCN4 tetramerization domain (MKQIEDKLEEILSKLYHIENELARIKKLLGE; GCN4-pLI) [11] and a BamH1 restriction endonuclease cleavage site (encoding amino acids, GS). The resulting constructs were transiently transfected into HEK293T cells, and the expressed rNA was purified from the expression medium using strep-tactin sepharose (IBA), as described [11]. The purified rNA was dialyzed against PBS using Slide-A-Lyzer dialysis cassettes, 20 MWCO (Thermo Fischer Scientific, Rockford, IL, USA).

The enzymatic activity of recombinant NA preparations was determined using the substrate, 4-methylumbelliferyl- $\alpha$-D- $N$-acetylneuraminic acid (4-MU-NANA), as described earlier [30]. In this assay, fluorescent 4-methylumbelliferone (4-MU) is quantitated after cleavage from 4-MU-NANA. Reactions were performed in 96-well plates, using $0.4 \mathrm{~mL}$ reaction buffer $(1 \mathrm{mg} / \mathrm{mL}$ bovine serum albumin, $150 \mathrm{mM} \mathrm{NaCl}, 30 \mathrm{mM}$ Na-MES, pH 6.5) per well. Eight serial five-fold dilutions of the different recombinant NAs in reaction buffer were made with a starting concentration of $50 \mathrm{ng} / \mathrm{mL}$. Then, 4-MU-NANA substrate was added to a concentration of $26 \mu \mathrm{M}$. The plate also contained eight standards of 4-MU $(0-3.3 \mu \mathrm{M})$. Plates were sealed with adhesive foil and incubated at $37^{\circ} \mathrm{C}$ for $60 \mathrm{~min}$. Enzyme reactions were stopped by the addition of $100 \mu \mathrm{L}$ stop buffer (180 mM glycine, $\mathrm{pH} 10.7)$. Fluorescence of 4-MU was measured (excitation $365 \mathrm{~nm}$, emission $450 \mathrm{~nm}$ ) using a GloMax Multi fluorometer (Promega, Fitchburg, WI). A standard curve of 4-MU concentrations and fluorescence data was generated. The amount of 4-MU product formed by the different NA preparations was then derived from fluorescence data by interpolation in the standard curve and used for calculation of the specific enzymatic activity.

The inhibition of rNA enzymatic activity by yeast-produced VHHs was measured using a different NA assay that uses fetuin as a substrate and is more suitable for measuring inhibition by antibodies [9]. In this assay [31], fetuin is adsorbed on ELISA plates and treated with NA, resulting in the removal of terminal sialic acid residues from fetuin, which allows peanut agglutinin lectin (PNA) binding to fetuin. Briefly, polystyrene 96-well plates were coated with $50 \mathrm{mg} / \mathrm{L}$ fetuin in $0.05 \mathrm{M}$ carbonate/bicarbonate buffer, $\mathrm{pH} 9.6$ (coating buffer), overnight at $4{ }^{\circ} \mathrm{C}$. Two-fold dilution series of $1 \mu \mathrm{g} / \mathrm{mL}$ VHHs were first incubated for $1 \mathrm{~h}$ with concentrations of the homologous rNA, which results in $90 \%$ of the maximal NA activity $(87.5 \mathrm{ng} / \mathrm{mL} \mathrm{rN} 2,87.5 \mathrm{ng} / \mathrm{mL} \mathrm{rN} 3,1 \mathrm{ng} / \mathrm{mL} \mathrm{rN} 7,1 \mathrm{ng} / \mathrm{mL} \mathrm{rN} 8$ or $300 \mathrm{ng} / \mathrm{mL} \mathrm{rN} 9$ ) in PBS with 1\% BSA and $6 \mathrm{mM}$ calcium chloride. VHH-rNA mixtures were then transferred to the fetuin-coated plates, followed by another $30 \mathrm{~min}$ incubation. Plates were subsequently incubated with $2.5 \mu \mathrm{g} / \mathrm{mL}$ PNA-PO conjugate and bound conjugate was detected, as described below (Section 3.7). The absorbance at $450 \mathrm{~nm}$ in the absence of VHH was defined as $100 \%$ rNA activity. The $\mathrm{VHH}$ concentration required to inhibit $50 \%$ of the rNA activity $\left(\mathrm{IC}_{50}\right)$ was then interpolated from $\mathrm{VHH}$ concentration versus absorbance values.

\subsection{Preparation of Purified Influenza Viruses}

Influenza viruses (Table 8) were propagated on embryonated eggs or Madin Darby canine kidney cells that grow serum-free in suspension (MDCK-SFS cells) [32]. Viral particles were purified from 
sucrose density gradients, as described previously [33], and buffer was exchanged to $100 \mathrm{mM} \mathrm{NaCl}$, $10 \mathrm{mM}$ Tris. $\mathrm{Cl} \mathrm{pH}$ 7.5, $1 \mathrm{mM}$ EDTA. The protein concentration was determined using the Bio-Rad (Hercules, CA) protein assay and a bovine immunoglobulin standard.

Table 8. Influenza A virus strains used.

\begin{tabular}{|c|c|c|c|c|c|}
\hline \multirow[b]{2}{*}{ Subtype } & \multirow[b]{2}{*}{ Strain } & \multicolumn{4}{|c|}{ Llama $^{a}$} \\
\hline & & 3049 & 3050 & 3466 & 3467 \\
\hline H1N1 & A/Puerto Rico/8/1934 & & & & \\
\hline H7N1 & A/chicken/Italy/1067/1999 & + & & & \\
\hline $\mathrm{H} 5 \mathrm{~N} 2$ & $\mathrm{~A} /$ mallard/Netherlands/2/2005 & + & & & \\
\hline H6N2 & A/turkey/Massachusetts/1965 & & & & \\
\hline H9N2 & A/duck/Germany/R113/1995 & & & + & \\
\hline $\mathrm{H} 2 \mathrm{~N} 3$ & A/ostrich/Netherlands/03006814/2003 & & + & & \\
\hline H16N3 & A/black-headed gull/Sweden/4/1999 & & & & + \\
\hline H8N4 & A/mallard/Netherlands/06026212/2006 & & + & & \\
\hline H1N5 & A/turkey/Netherlands/07014290/2007 & & & + & \\
\hline H6N5 & A/turkey/Netherlands/06001571-041Tr/2006 & & + & & \\
\hline H12N5 & A/duck/Alberta/60/1976 & & & + & \\
\hline H11N6 & A/duck/England/750/1956 & & & & + \\
\hline H13N6 & A/black-headed gull/Sweden/1/1999 & & & & + \\
\hline H14N6 & A/mallard/Gurjev/244/1982 & & & & + \\
\hline $\mathrm{H} 5 \mathrm{~N} 7$ & A/mallard/Denmark/75-64650/2003 & & & & \\
\hline H7N7 & A/swan/Netherlands/06003448/2006 & + & & & \\
\hline H3N8 & A/mallard/Netherlands/06027358/2006 & & & & + \\
\hline H4N8 & A/parakeet/Netherlands/1/1978 & & & + & \\
\hline $\mathrm{H} 10 \mathrm{~N} 8$ & $\mathrm{~A} /$ mallard/Netherlands/06014516/2006 & & + & & \\
\hline H5N9 & A/chicken/Italy/22A/1998 & & + & & \\
\hline H5N9 & A/turkey/Wisconsin/1968 & & & & \\
\hline H15N9 & A/shearwater/Australia/2576/2002 & & + & & \\
\hline
\end{tabular}

${ }^{a}$ Virus strains used for immunization of llamas 3049, 3050, 3466 and 3467.

\subsection{Phage Display Selection of Antigen Binding VHHs}

\subsubsection{Llama Immunization and Phage Library Construction}

The basic procedure for llama (Lama glama) immunizations has been described previously [19]. Four llamas were immunized with mixtures of different influenza virus strains (Table 8) using $100 \mu \mathrm{g}$ purified influenza virus of each strain that was emulsified with Stimune adjuvant (Prionics AG, Schlieren, Switzerland). Similar booster immunizations were given 4 and 7 weeks later. Five and eight weeks after primary immunization, the VHH repertoire was amplified by RT-PCR from peripheral blood lymphocytes and inserted into phage display vector, pRL144, as earlier described [19]. Most phage display selections were done using phage libraries prepared from the 8-weeks post-immunization sample. 


\subsubsection{Phage Display Selection}

Phage display selections were performed by two consecutive rounds of biopanning [34] in 96-well polystyrene ELISA plates (Greiner, Cat. No. 655092), using $100 \mu \mathrm{L} /$ well for each incubation. Many variations on the procedure were used. In general, antigen was immobilized to ELISA plates at three serial ten-fold dilutions and including a control without antigen. Influenza viruses were normally coated at concentrations of $1,0.1$ and $0.01 \mu \mathrm{g} / \mathrm{mL}$ in $0.05 \mathrm{M}$ carbonate/bicarbonate buffer, $\mathrm{pH} 9.6$ (coating buffer), overnight at $4{ }^{\circ} \mathrm{C}$. Recombinant NA was coated at concentrations of $1,0.1$ and $0.01 \mu \mathrm{g} / \mathrm{mL}$ in the case of enzymatically active preparations, but ten-fold higher concentrations in the case of inactive preparations (rN1, rN4 and rN5; Table 3). Occasionally, rNA preparations were captured in solution on plates coated with $2 \mu \mathrm{g} / \mathrm{mL}$ streptavidin in PBS (Roche Applied Science). For specific immobilization of NA, plates were coated with $1 \mu \mathrm{g} / \mathrm{mL}$ VHHs in coating buffer and purified virus preparations $(10 \mu \mathrm{g} / \mathrm{mL})$ were separately incubated in PBS containing 1\% Triton X-100 for 30 min at room temperature. This preparation was then captured on plates coated with $\mathrm{VHH}$ at ten-fold $(1 \mu \mathrm{g} / \mathrm{mL})$ or 100 -fold $(0.1 \mu \mathrm{g} / \mathrm{mL})$ dilution in PBS buffer containing $1 \%$ milk and $0.05 \%$ Tween-20 (PBSTM) for $1 \mathrm{~h}$ at room temperature. Control wells were also coated with VHH without subsequent incubation with influenza virus, and wells without VHH coating were incubated with $1 \mu \mathrm{g} / \mathrm{mL}$ influenza virus. Plates were then incubated with $0.5 \times 10^{10}$ transducing units $/ \mathrm{mL}$ phages. Occasionally, phages were preincubated in PBSTM containing $10 \mu \mathrm{g} / \mathrm{mL}$ virus of a different type than used for panning to compete for binding to common antigenic sites. Bound phages were eluted by incubation with $1 \mathrm{mg} / \mathrm{mL}$ trypsin in PBS for $30 \mathrm{~min}$ at $37^{\circ} \mathrm{C}$ and immediately transduced to E. coli TG1 cells. In each selection round, we performed a parallel phage ELISA simultaneous with the phage display selection for evaluation of the phage display selection. For this purpose, a duplex plate containing similar concentrations and types of antigen and phage was incubated with a peroxidase-conjugated monoclonal antibody against the M13 p8 coat protein (GE Healthcare, Little Chalfont, UK) instead of incubation with trypsin. The amount of antigen specific phage bound was then measured by ELISA (section 3.7).

\subsubsection{Production of Soluble VHH in E. coli}

After the second panning round phages were transduced to E. coli TG1 cells, individual colonies were picked and the VHH genes were induced with $1 \mathrm{mM}$ isopropyl $\beta$-D-thiogalactopyranoside. Recombinant VHHs, extracted from the periplasm, were tested for binding to rNA proteins or whole influenza virus by ELISA at ten-fold dilution of E. coli culture supernatant. VHHs produced in E. coli using vector pRL144 are indicated by the suffix "Y". For subsequent use as capturing VHH in phage display selections, the VHHs IV176Y, IV224Y, IV237Y and IV297Y were purified from culture supernatant using immobilized-metal affinity chromatography [34].

\subsection{Sequence Analysis}

Sequence analysis of the VHH encoding region was performed, as described previously [20]. The deduced VHH amino acid sequences were aligned according to the IMGT system [35] for alignment, 
numbering and complementarity-determining region (CDR) definition of immunoglobulins. Potential $\mathrm{N}$-glycosylation sites were defined as Asn-X-Ser/Thr, where $\mathrm{X}$ represents any amino acid, except Pro.

A phylogenetic tree of the nine NA protein sequences used for production of rNA (Table 3) was generated with the program, PhyML3.0 [36].

\subsection{Yeast Production, Deglycosylation and Biotinylation of VHHs}

Plasmid pRL188 [37] is suitable for the insertion of VHH encoding fragments into the PstI and $B s t$ EII sites and subsequent yeast production of VHHs with a C-terminal extension consisting of the llama long hinge region and a hexahistidine tag (amino acid sequence EPKTPKPQPQPQPQPQPNPTTESKCPHHHHHH). Such VHHs are indicated by the suffix, "F". Expression of VHHs in Saccharomyces cerevisiae under control of the GAL7 promoter and directed into the growth medium by fusion to the invertase signal peptide and the increased expression levels obtained by using the MIRY type vector pRL44 has been described previously [37]. The VHHs were purified from culture supernatant using IMAC. Proteins were concentrated and the buffer exchanged to phosphate-buffered saline by use of 3-kDa molecular weight cut-off (MWCO) centrifugal concentration devices (Ultracel regenerated nitrocellulose membrane, Millipore, Bedford, MA). The protein concentration was determined using the Bio-Rad protein assay and a bovine immunoglobulin standard. VHHs were deglycosylated by $3 \mathrm{~h}$ incubation of $0.5 \mathrm{mg} / \mathrm{mL}$ VHH with $2 \mathrm{U} / \mathrm{mL}$ endoglycosidase H (Roche Applied Science, Mannheim, Germany) at $37{ }^{\circ} \mathrm{C}$ in $50 \mathrm{mM}$ sodium citrate, $\mathrm{pH}$ 5.5. Yeast-produced VHHs were biotinylated at a weight-ratio of protein to biotin of 10 using amine-reactive sulfo- $N$-hydroxysuccinimide-LC-biotin (Pierce, Rockford, IL). Buffer was exchanged to PBS and free biotin removed 3 times at least 10-fold dilution and concentration using 3-kDa MWCO concentration devices.

\subsection{ELISAs}

\subsubsection{Indirect ELISA for Analyzing VHH Binding to Influenza Antigens}

High binding polystyrene 96-well plates (Greiner, Solingen, Germany) were coated overnight at $4{ }^{\circ} \mathrm{C}$ with $1 \mu \mathrm{g} / \mathrm{mL} \mathrm{rNA}$ in PBS or $2 \mu \mathrm{g} / \mathrm{mL}$ purified influenza virus in coating buffer at $100 \mu \mathrm{L} / \mathrm{well}$. Residual sites were blocked for $2 \mathrm{~h}$ at room temperature with $1 \%$ skimmed milk in ELISA-buffer (1\% skimmed milk; 0.05\% Tween-20; $0.5 \mathrm{M} \mathrm{NaCl} ; 2.7 \mathrm{mM} \mathrm{KCl} ; 2.8 \mathrm{mM} \mathrm{KH} \mathrm{PO}_{4} ; 8.1 \mathrm{mM} \mathrm{Na} \mathrm{HPO}_{4}$; $\mathrm{pH}$ 7.4). Plates were subsequently incubated with either yeast-produced VHH $(1 \mu \mathrm{g} / \mathrm{mL})$ that was either biotinylated or not biotinylated or E. coli produced VHH (ten-fold diluted E. coli culture supernatant). Bound yeast-produced VHH was detected with $1 \mu \mathrm{g} / \mathrm{mL}$ peroxidase (PO)-conjugated anti-his6 tag monoclonal antibody (Roche Applied Science) using non-biotinylated VHH or $0.5 \mu \mathrm{g} / \mathrm{mL}$ PO-conjugated streptavidin (Jackson ImmunoResearch Laboratories Inc., West Grove, PA, USA) using biotinylated VHH. Bound E. coli-produced VHH was detected with $1 \mu \mathrm{g} / \mathrm{mL}$ PO-conjugated anti-myc tag monoclonal antibody (anti-myc-PO; Roche Applied Science). Bound PO was stained with 3,3',5,5' tetramethylbenzidine. The reaction was stopped by adding half a volume $0.5 \mathrm{M} \mathrm{H}_{2} \mathrm{SO}_{4}$. The absorbance at $450 \mathrm{~nm}$ was then measured using a Multiskan Ascent spectrophotometer (Thermo Labsystems, Helsinki, Finland). 


\subsubsection{Sandwich ELISA for Analyzing VHH Binding to Influenza Antigens}

This ELISA was performed similar to the indirect ELISA (see previous Section). However, ELISA plates were coated with $1 \mu \mathrm{g} / \mathrm{mL}$ IV512F or without VHH in coating buffer and then incubated with $2 \mu \mathrm{g} / \mathrm{mL}$ Triton X-100 solubilized influenza virus (see Section 3.4.2) of various subtypes. Bound NA of subtypes N1 to N9 was then detected using nine different biotinylated VHHs specific for these subtypes: IV171F, deglycosylated IV81F, IV191F, IV215F, IV451F, IV514F, IV242F, IV268F and IV295F. Bound biotinylated VHH was then detected, as described in the previous section.

\section{Conclusions}

We isolated a diverse panel of $188 \mathrm{VHHs}$ binding to the nine NA subtypes of influenza A virus that occur in birds. It is unknown whether any of these VHHs also bind to a tenth NA subtype that was recently identified in bats [2]. We characterized the antigen binding specificity of 64 yeast-produced VHHs. This highly diverse set of VHHs, as also exemplified by their predominantly different CDR3 sequences (54 CDR3 groups), was derived from only four llamas immunized with virus antigens. This illustrates the ability to isolate many different VHHs from llamas immunized with multiple antigens by phage display selection, especially taking into account that we also isolated more than 50 binders against fifteen of the sixteen $\mathrm{H}$ subtypes from these same four llamas (results not shown). This notion is consistent with others [38], who state that they "... were impressed by the ability of a single llama to deliver a broad range of ligands with good sensitivity and mostly exquisite specificity, after being immunized with relatively low amounts ... of multiple immunogens that have been shown to be far from native and far from optimal in eliciting the highest antibody titers." Since NP and HA are more immunogenic than NA, we had to optimize our phage display selection strategy to retrieve NA binders. Selections using whole virus by alternating selections on different $\mathrm{N}$ subtypes or using competition with the same HA subtype were not successful. However, selections yielded predominantly NA binders when using recombinant NA, especially when it was enzymatically active.

The newly identified VHHs could be used in several applications. VHHs have a high physicochemical stability [14], which makes them highly suited for use in biosensor applications [15] or immunoaffinity purification methods, since the biosensor surface or affinity column containing immobilized VHHs can be efficiently regenerated without loss of antigen binding capacity [39]. Thus, VHHs could also be used for purification of NA antigen for industrial vaccine production or development of novel biosensors for sensitive influenza detection. Alternatively, they can be used for development of ELISAs for specifically measuring serological antibody responses against the different $\mathrm{N}$ subtypes, for use in DIVA vaccination strategies [4]. Such work is currently in progress in our lab. There is also interest in the measurement of the NA content of influenza vaccines, since this contributes to vaccine efficacy [12]. We also isolated at least one VHH that binds to NA of most influenza strains, although often with low absorbance value, making it unlikely that this VHH is suited for such purposes. However, there are several possibilities for improvement of the currently used approach to stimulate isolation of cross-reacting VHHs. Firstly, consecutive selections should be done on NAs of different subtypes, instead of selection on the same N subtype, as done here. Secondly, since immunization with NA as present in whole virus results in reduced immunogenicity of NA [9,11], llamas should be immunized with rNA, followed by selection on NA solubilized from 
virus. Thirdly, consecutive immunization of one llama with rNAs of different subtypes could further direct the immune response to conserved epitopes, similar to an approach used for isolating antibodies to conserved HA epitopes [40].

There is currently an interest in the use of antibodies against influenza virus for therapeutic use in humans. These studies mainly focus on conventional antibodies against a conserved epitope in the HA stem [23-25], although there is a recent example of a protective antibody against NA [41]. Furthermore, VHHs against the less conserved HA globular head have been evaluated for antiviral use $[17,42,43]$. Therefore, it would be interesting to determine whether the broadly cross-reactive NA binding VHH IV512F inhibits NA activity, which could make it useful for human therapy.

\section{Acknowledgments}

This research was partially funded by the Impulse Veterinary Avian Influenza Research in the Netherlands, program of the Economic Structure Enhancement Fund. The authors thank Berend Jan Bosch of Utrecht University for advice on recombinant NA production.

\section{References and Notes}

1. Bouvier, N.M.; Palese, P. The biology of influenza viruses. Vaccine 2008, 26 (Suppl. 4), D49-D53.

2. Tong, S.; Li, Y.; Rivailler, P.; Conrardy, C.; Castillo, D.A.; Chen, L.M.; Recuenco, S.; Ellison, J.A.; Davis, C.T.; York, I.A.; et al. A distinct lineage of influenza A virus from bats. Proc. Natl. Acad. Sci. USA 2012, 109, 4269-4274.

3. Fouchier, R.A.; Schneeberger, P.M.; Rozendaal, F.W.; Broekman, J.M.; Kemink, S.A.; Munster, V.; Kuiken, T.; Rimmelzwaan, G.F.; Schutten, M.; et al. Avian influenza A virus (H7N7) associated with human conjunctivitis and a fatal case of acute respiratory distress syndrome. Proc. Natl. Acad. Sci. USA 2004, 101, 1356-1361.

4. Capua, I.; Cattoli, G. Diagnosing avian influenza infection in vaccinated populations by systems for differentiating infected from vaccinated animals (DIVA). Dev. Biol. 2007, 130, 137-143.

5. Kim, J.N.; Byun, S.H.; Kang, S.Y.; Mo, I.P. Evaluation of neuraminidase antigen based competitive enzyme-linked immunosorbent assay in chickens vaccinated with avian influenza inactivated vaccine. Avian Dis. 2010, 54, 682-685.

6. Liu, Y.; Mundt, E.; Mundt, A.; Sylte, M.; Suarez, D.L.; Swayne, D.E.; Garcia, M. Development and evaluation of an avian influenza, neuraminidase subtype 1, indirect enzyme-linked immunosorbent assay for poultry using the differentiation of infected from vaccinated animals control strategy. Avian Dis. 2010, 54, 613-621.

7. Moreno, A.; Brocchi, E.; Lelli, D.; Gamba, D.; Tranquillo, M.; Cordioli, P. Monoclonal antibody based ELISA tests to detect antibodies against neuraminidase subtypes 1,2 and 3 of avian influenza viruses in avian sera. Vaccine 2009, 27, 4967-4974.

8. Gamblin, S.J.; Skehel, J.J. Influenza hemagglutinin and neuraminidase membrane glycoproteins. J. Biol. Chem. 2010, 285, 28403-28409.

9. Marcelin, G.; Sandbulte, M.R.; Webby, R.J. Contribution of antibody production against neuraminidase to the protection afforded by influenza vaccines. Rev. Med. Virol. 2012, 22, 267-279. 
10. Johansson, B.E.; Bucher, D.J.; Kilbourne, E.D. Purified influenza virus hemagglutinin and neuraminidase are equivalent in stimulation of antibody response but induce contrasting types of immunity to infection. J. Virol. 1989, 63, 1239-1246.

11. Bosch, B.J.; Bodewes, R.; de Vries, R.P.; Kreijtz, J.H.; Bartelink, W.; van Amerongen, G.; Rimmelzwaan, G.F.; de Haan, C.A.; Osterhaus, A.D.; Rottier, P.J. Recombinant soluble, Multimeric HA and NA exhibit distinctive types of protection against pandemic swine-origin 2009 A(H1N1) influenza virus infection in ferrets. J. Virol. 2010, 84, 10366-10374.

12. Gravel, C.; Li, C.; Wang, J.; Hashem, A.M.; Jaentschke, B.; Xu, K.W.; Lorbetskie, B.; Gingras, G.; Aubin, Y.; Van Domselaar, G.; et al. Qualitative and quantitative analyses of virtually all subtypes of influenza A and B viral neuraminidases using antibodies targeting the universally conserved sequences. Vaccine 2010, 28, 5774-5784.

13. Sandbulte, M.R.; Westgeest, K.B.; Gao, J.; Xu, X.; Klimov, A.I.; Russell, C.A.; Burke, D.F.; Smith, D.J.; Fouchier, R.A.; Eichelberger, M.C. Discordant antigenic drift of neuraminidase and hemagglutinin in H1N1 and H3N2 influenza viruses. Proc. Natl. Acad. Sci. USA 2011, 108, 20748-20753.

14. Harmsen, M.M.; De Haard, H.J. Properties, Production, and applications of camelid singledomain antibody fragments. Appl. Microbiol. Biotechnol. 2007, 77, 13-22.

15. Huang, L.; Muyldermans, S.; Saerens, D. Nanobodies(R): Proficient tools in diagnostics. Expert Rev. Mol. Diagn. 2010, 10, 777-785.

16. Hamers-Casterman, C.; Atarhouch, T.; Muyldermans, S.; Robinson, G.; Hamers, C.; Songa, E.B.; Bendahman, N.; Hamers, R. Naturally occurring antibodies devoid of light chains. Nature 1993, 363, 446-448.

17. Hultberg, A.; Temperton, N.J.; Rosseels, V.; Koenders, M.; Gonzalez-Pajuelo, M.; Schepens, B.; Ibanez, L.I.; Vanlandschoot, P.; Schillemans, J.; Saunders, M.; et al. Llama-derived single domain antibodies to build multivalent, superpotent and broadened neutralizing anti-viral molecules. PLoS One 2011, 6, e17665.

18. Jahnichen, S.; Blanchetot, C.; Maussang, D.; Gonzalez-Pajuelo, M.; Chow, K.Y.; Bosch, L.; De Vrieze, S.; Serruys, B.; Ulrichts, H.; Vandevelde, W.; et al. CXCR4 nanobodies (VHH-based single variable domains) potently inhibit chemotaxis and HIV-1 replication and mobilize stem cells. Proc. Natl. Acad. Sci. USA 2010, 107, 20565-20570.

19. Harmsen, M.M.; Van Solt, C.B.; Fijten, H.P.D.; Van Setten, M.C. Prolonged in vivo residence times of llama single-domain antibody fragments in pigs by binding to porcine immunoglobulins. Vaccine 2005, 23, 4926-4934.

20. Harmsen, M.M.; Ruuls, R.C.; Nijman, I.J.; Niewold, T.A.; Frenken, L.G.J.; de Geus, B. Llama heavy-chain $\mathrm{V}$ regions consist of at least four distinct subfamilies revealing novel sequence features. Mol. Immunol. 2000, 37, 579-590.

21. Lu, J.; Sloan, S.R. An alternating selection strategy for cloning phage display antibodies. J. Immunol. Methods 1999, 228, 109-119.

22. Wu, R.; Hu, S.; Xiao, Y.; Li, Z.; Shi, D.; Bi, D. Development of indirect enzyme-linked immunosorbent assay with nucleoprotein as antigen for detection and quantification of antibodies against avian influenza virus. Vet. Res. Commun. 2007, 31, 631-641. 
23. Ekiert, D.C.; Bhabha, G.; Elsliger, M.A.; Friesen, R.H.; Jongeneelen, M.; Throsby, M.; Goudsmit, J.; Wilson, I.A. Antibody recognition of a highly conserved influenza virus epitope. Science 2009, 324, 246-251.

24. Ekiert, D.C.; Friesen, R.H.; Bhabha, G.; Kwaks, T.; Jongeneelen, M.; Yu, W.; Ophorst, C.; Cox, F.; Korse, H.J.; Brandenburg, B.; et al. A highly conserved neutralizing epitope on group 2 influenza A viruses. Science 2011, 333, 843-850.

25. Throsby, M.; van den Brink, E.; Jongeneelen, M.; Poon, L.L.; Alard, P.; Cornelissen, L.; Bakker, A.; Cox, F.; van Deventer, E.; Guan, Y.; et al. Heterosubtypic Neutralizing Monoclonal Antibodies Cross-Protective against H5N1 and H1N1 Recovered from Human IgM Memory B Cells. PLoS ONE 2008, 3, e3942.

26. Marks, J.D.; Ouwehand, W.H.; Bye, J.M.; Finnern, R.; Gorick, B.D.; Voak, D.; Thorpe, S.J.; Hughes-Jones, N.C.; Winter, G. Human antibody fragments specific for human blood group antigens from a phage display library. Biotechnology 1993, 11, 1145-1149.

27. Desselberger, U. Preparation-conditioned changes of the antigenicity of influenza virus neuraminidases. Arch. Virol. 1977, 53, 335-349.

28. Lauwereys, M.; Arbabi Ghahroudi, M.; Desmyter, A.; Kinne, J.; Holzer, W.; De Genst, E.; Wyns, L.; Muyldermans, S. Potent enzyme inhibitors derived from dromedary heavy-chain antibodies. EMBO J. 1998, 17, 3512-3520.

29. Stijlemans, B.; Conrath, K.; Cortez-Retamozo, V.; Van Xong, H.; Wyns, L.; Senter, P.; Revets, H.; De Baetselier, P.; Muyldermans, S.; Magez, S. Efficient targeting of conserved cryptic epitopes of infectious agents by single domain antibodies. African trypanosomes as paradigm. J. Biol. Chem. 2004, 279, 1256-1261.

30. Kalbfuss, B.; Knochlein, A.; Krober, T.; Reichl, U. Monitoring influenza virus content in vaccine production: precise assays for the quantitation of hemagglutination and neuraminidase activity. Biologicals 2008, 36, 145-161.

31. Lambré, C.R.; Terzidis, H.; Greffard, A.; Webster, R.G. An enzyme-linked lectin assay for sialidase. Clin. Chim. Acta 1991, 198, 183-193.

32. van Wielink, R.; Kant-Eenbergen, H.C.; Harmsen, M.M.; Martens, D.E.; Wijffels, R.H.; CocoMartin, J.M. Adaptation of a Madin-Darby canine kidney cell line to suspension growth in serumfree media and comparison of its ability to produce avian influenza virus to Vero and BHK21 cell lines. J. Virol. Methods 2011, 171, 53-60.

33. Arora, D.J.; Tremblay, P.; Bourgault, R.; Boileau, S. Concentration and purification of influenza virus from allantoic fluid. Anal. Biochem. 1985, 144, 189-192.

34. McCafferty, J.; Johnson, K.S. Construction and screening of antibody display libraries. In Phage Display of Peptides and Proteins; Kay, B.K., Winter, J., McCafferty, J., Eds.; Academic Press: San Diego, CA, USA, 1996; pp. 79-111.

35. Lefranc, M.P. IMGT, The International ImMunoGeneTics Information System, http://imgt.cines.fr. Methods Mol. Biol. 2004, 248, 27-49.

36. Dereeper, A.; Guignon, V.; Blanc, G.; Audic, S.; Buffet, S.; Chevenet, F.; Dufayard, J.F.; Guindon, S.; Lefort, V.; Lescot, M.; et al. Phylogeny.fr: Robust phylogenetic analysis for the non-specialist. Nucleic Acids Res. 2008, 36, W465-W469. 
37. Harmsen, M.M.; Van Solt, C.B.; Fijten, H.P.D.; Van Keulen, L.; Rosalia, R.A.; Weerdmeester, K.; Cornelissen, A.H.M.; De Bruin, M.G.M.; Eblé, P.L.; Dekker, A. Passive immunization of guinea-pigs with llama single-domain antibody fragments against foot-and-mouth disease. Vet. Microbiol. 2007, 120, 193-206.

38. Conway, J.O.; Sherwood, L.J.; Collazo, M.T.; Garza, J.A.; Hayhurst, A. Llama single domain antibodies specific for the 7 botulinum neurotoxin serotypes as heptaplex immunoreagents. PLoS One 2010, 5, e8818.

39. Verheesen, P.; ten Haaft, M.R.; Lindner, N.; Verrips, C.T.; de Haard, J.J. Beneficial properties of single-domain antibody fragments for application in immunoaffinity purification and immunoperfusion chromatography. Biochim. Biophys. Acta 2003, 1624, 21-28.

40. Wang, T.T.; Tan, G.S.; Hai, R.; Pica, N.; Petersen, E.; Moran, T.M.; Palese, P. Broadly protective monoclonal antibodies against $\mathrm{H} 3$ influenza viruses following sequential immunization with different hemagglutinins. PLoS Pathogens 2010, 6, e1000796.

41. Shoji, Y.; Chichester, J.A.; Palmer, G.A.; Farrance, C.E.; Stevens, R.; Stewart, M.; Goldschmidt, L.; Deyde, V.; Gubareva, L.; Klimov, A.; et al. An influenza N1 neuraminidase-specific monoclonal antibody with broad neuraminidase inhibition activity against H5N1 HPAI viruses. Human Vac. 2011, 7, 199-204.

42. Ibanez, L.I.; De Filette, M.; Hultberg, A.; Verrips, T.; Temperton, N.; Weiss, R.A.; Vandevelde, W.; Schepens, B.; Vanlandschoot, P.; Saelens, X. Nanobodies with in vitro neutralizing activity protect mice against H5N1 influenza virus infection. J. Infect. Dis. 2011, 203, 1063-1072.

43. Tillib, S.V.; Ivanova, T.I.; Vasilev, L.A.; Rutovskaya, M.V.; Saakyan, S.A.; Gribova, I.Y.; Tutykhina, I.L.; Sedova, E.S.; Lysenko, A.A.; Shmarov, M.M.; et al. Formatted single-domain antibodies can protect mice against infection with influenza virus (H5N2). Antiviral Res. 2013, 97, 245-254.

(C) 2013 by the authors; licensee MDPI, Basel, Switzerland. This article is an open access article distributed under the terms and conditions of the Creative Commons Attribution license (http://creativecommons.org/licenses/by/3.0/). 